ISSN: 0213-2060

DOI: https://doi.org/10.14201/shhme201735287117

\title{
ESTRUCTURAS DE POBLAMIENTO EN TOLOX (MÁLAGA). LA OCUPACIÓN DEL TERRITORIO Y LA EXPLOTACIÓN DE SUS RECURSOS EN LA EDAD MEDIA
}

\author{
Structures of Settlement in Tolox (Málaga-Spain). Occupation of Land \\ and Exploitation of its Resources in the Middle Ages \\ Francisco MARMOLEJO CANTOS \\ Universidad de Málaga. Campus de Teatinos, s/n. E-39071 MÁLAGA. C. e.: arqueologiacoin@gmail.com
}

Recibido: 2016-02-18

Revisado: 2017-01-09

Aceptado: 2017-11-03

RESUMEN: Estudio descriptivo y analítico sobre el poblamiento medieval en la cuenca alta de Río Grande, en los antiguos límites territoriales de la cora de Rayya. Bajo un enfoque fundamentalmente arqueológico e histórico, se descubren estructuras locales plenamente autosuficientes, lejanas al control del Estado y ajenas a los grandes procesos de concentración de excedentes, lo que permite explicar las dificultades para la ocupación islámica y su implantación efectiva en el territorio.

Palabras clave: Dispositivo defensivo; Comunidades rurales; Arqueología espacial; AlAndalus.

ABSTRACT: Descriptive and analytical study of medieval settlement in the upper basin of the Rio Grande, in Malaga's western boundary (Spain). Under a mainly archaeological and historical approach, we have discovered local structures fully self-sufficient, distant to the State control and unknown to the great surpluses concentration processes, which helps explain the difficulties of the Islamic occupation and its implementation within it's territory.

Keywords: Defensive system; Rural communities; Landscape archeology; Al Andalus. 
ESTRUCTURAS DE POBLAMIENTO EN TOLOX (MÁLAGA). LA OCUPACIÓN DEL TERRITORIO Y LA EXPLOTACIÓN DE SUS RECURSOS EN LA EDAD MEDIA FRANCISCO MARMOLEJO CANTOS

SUMARIO: 0 Introducción. 1 Sistema defensivo de la población. 1.1 Visión de conjunto. 1.2 Castillo y murallas. 1.3 Casa fuerte y torre almenara. 2 Fortaleza de la Teja. 3 Castillo de Cerro Corona. 4 Despoblado de Murta. 5 Necrópolis del partido de Lobato. 6 Despoblado de Robaquel. 7 Llanos del Tejar. 8 Llanillos del Piloncillo. 9 Despoblado del Moralejo. 10 Villares de Boliges. 11 Ardite. 12 Conclusiones. 13 Referencias bibliográficas.

\section{INTRODUCCIÓN}

Se dan los primeros pasos para dar a conocer las formas de poblamiento y el patrimonio andalusí que atesora esta localidad, hasta el momento inédito y desconocido para la comunidad científica y el gran público en general ${ }^{1}$. Documentamos un total de tres fortalezas y nueve yacimientos de época medieval en su actual término municipal, sobre los que hemos dado parte para su catalogación y protección. Se ha visto la necesidad de conjugar en este trabajo divulgación y rigor científico, resumiendo los datos para su mejor comprensión y, con toda razón, por falta de espacio en esta publicación.

Desde un principio, nuestra investigación se vio condicionada por el vacío bibliográfico que padece la localidad, sin duda preocupante en los tiempos que corren, motivado en gran medida por la dura geomorfología del territorio y el desapego por el medio rural ${ }^{2}$. Hemos preferido estructurar el trabajo en dos bloques, el primero de ellos entra en detalle sobre el sistema defensivo de la actual población, al que aún no se le ha prestado ninguna atención y la poca existente necesita seriamente una revisión historiográfica. En la segunda parte, en cambio, planteamos como desarrollo fundamental estudiar el poblamiento rural de época andalusí, pese a que algunos enclaves tienen un origen de mayor antigüedad.

El término de Tolox, enclavado en el sector centro-occidental de la provincia de Málaga, marca la transición entre la serranía de Ronda y el valle del Guadalhorce. Se sitúa en el extremo occidental de las cordilleras Béticas y alberga en su término la mayor altitud

1 Este artículo se enmarca en el proyecto «Investigación y estudios medievales en la cuenca fluvial de Río Grande», cuyos resultados fueron expuestos parcialmente en la conferencia impartida por el autor en el municipio de Tolox el 5 de diciembre de 2015, bajo el título "Castillos y despoblados medievales de Tolox", agradeciendo con estas palabras previas a los organizadores y al Excmo. Ayuntamiento, así como al personal del Museo Municipal.

Siglas y abreviaturas utilizadas: AGS = Archivo General de Simancas; AHPG = Archivo Histórico Provincial de Granada; AHPM = Archivo Histórico Provincial de Málaga; ACM = Archivo Catedral de Málaga; AMM = Archivo Municipal de Málaga IVDJ = Instituto Valencia de Don Juan .

2 La bibliografía arqueológica se reduce tan solo a tres artículos: PÉrez Berrocal, José Antonio. «Tres vasos decorados de la cueva de la Tinaja». Jábega, 1979, vol. 25, pp. 9-13; Pérez Berrocal, José Antonio y Moreno Wallace, Loreto. "Informe preliminar. Campaña de exploraciones en el complejo "Hoyos del Pilar" ". Monografías Espeleológicas, 1973, vol. 2, pp. 4-10; y Marmolejo Cantos, Francisco y Sánchez Guerra, Diego J. "La fortaleza de la Teja y la alquería de Gaimón. Un ḥiṣn con alquería en los confines de Monda y Tolox». Arqueología Medieval, n. ${ }^{\circ}$ 139, 2013, en https:/goo.gl/PCoAN0. De otro lado, en lo que a nosotros interesa, los artículos históricos disponibles se encuentran en Martínez EnAMOrado, Virgilio. "Apuntes sobre la villa de Tolox (Málaga) a partir de su libro de repartimiento (1572): una sociedad morisca en trance de desaparición». En Benlabbah, Fatiha y Chalkha, Achouak (coords.). Los moriscos y su legado desde ésta y otras laderas. Rabat: Instituto de Estudios Hispano-Lusos, 2010, pp. 397-422. López García, Esteban. «Regadío de origen andalusí en la Sierra de las Nieves. El caso de Tolox (1485-1572)». Takurunna, 2012, vol. 2, pp. 187-216. 
ESTRUCTURAS DE POBLAMIENTO EN TOLOX (MÁLAGA). LA OCUPACIÓN DEL TERRITORIO Y LA EXPLOTACIÓN DE SUS RECURSOS EN LA EDAD MEDIA FRANCISCO MARMOLEJO CANTOS

$(1.919 \mathrm{~m})$ del cuadrante suroccidental de la Península. En su territorio tienen origen dos importantes cursos fluviales: Río Grande (725 1/s) y Río Verde (750 1/s), ambos alimentados por el deshielo de la sierra de las Nieves y el régimen pluviométrico.

En líneas generales, los asentamientos medievales siguen la red fluvial tributaria de Río Grande, cuya cuenca alcanza hoy los $338,1 \mathrm{~km}^{2}$. La estructura de poblamiento se desenvuelve en un territorio aislado, inaccesible y alejado de los grandes centros de poder, con capacidad de atracción en épocas de conflicto, bien caracterizado por la dispersión espacial de los núcleos de hábitat, con la salvedad puntual advertida en el estrecho valle de la Alfaguara y en el arroyo de los Valles, donde existen indicios de concentración poblacional en núcleos muy reducidos y próximos entre sî́.

En los primeros siglos de al-Andalus se aprecia continuidad en la organización territorial tardoantigua, rasgo que perdura en otros contextos geográficos cercanos. La vida económica se sustenta en actividades productivas y extractivas, combinadas con actividades artesanales de manufactura, donde los pocos excedentes tendrían difícil acceso al mercado y se destinaban de forma inmediata al trueque. Ocupación predominante debió ser la explotación de los bosques para proveer de mineral y combustible al centro siderúrgico de Porticate, importante alquería que pudo convertirse en centro polarizador de los excedentes. La llegada del Islam y su implantación en el territorio se percibe claramente en el valle del río de los Horcajos, con asentamientos dedicados a una producción más especializada, basada en la explotación intensiva de sus terrazas fluviales. Si bien, parece razonable pensar que estos pequeños núcleos documentados debieron mantener una compleja relación con los grandes centros urbanos del entorno (Ronda, Málaga y Bobastro).

Del estudio llevado a cabo, es innegable la militarización del territorio con pequeñas guarniciones estratégicas, como se advierte en la cumbre de cerro Corona, controlando de forma inmediata los puertos de montaña. Siguiendo esta línea, los dos recintos castrales que hemos documentado de época altomedieval parecen surgir en la frontera interna conformada por la sierra de las Nieves, barrera montańosa difícil de franquear; ambos plenamente ocupados durante la fitna de Ibn Ḥafșūn, como demuestra la cerámica de los siglos Ix y x. Desaparecidas las necesidades defensivas serán abandonados, pero sobreviven las alquerías inmediatas en cotas inferiores, según comprobamos en Gaimón, despoblado vinculado claramente a la fortaleza de la Teja.

Hacia el siglo XII se advierten modificaciones sustanciales en las formas de asentamiento y claras diferencias en la organización económica, con un tímido acercamiento a las fértiles terrazas de Río Grande y, por ende, a las principales vías de comunicación. Decididamente, estas nuevas poblaciones prosperan con las primeras migraciones desde lugares mudéjares y el $\mathrm{Magreb}^{4}$, con especial intensidad en los siglos XIII y XIV, poniendo

3 Sería el caso de los despoblados de Murta, Llanillos del Piloncillo y Robaquel (margen izquierda del arroyo Alfaguara); villares de Arroyo Hondo, Puerto del Viento y Ardite (margen izquierda del arroyo de los Valles); y finalmente la alquería de los Valles, El Moralejo y los villares de Boliges (margen derecha del arroyo de los Valles).

4 Los movimientos migratorios que provienen del norte (lugares mudéjares y fronterizos) encuentran fácil explicación en la presión castellana y el avance militar; sin embargo, los que proceden del Magreb son mucho más complejos y, ciertamente, más selectivos en función de la edad y del sexo de los individuos. Aún así, tenemos claro que, en determinados periodos históricos, fue el Estado quien debió estimular y facilitar ese proceso. 
ESTRUCTURAS DE POBLAMIENTO EN TOLOX (MÁLAGA). LA OCUPACIÓN DEL TERRITORIO Y LA EXPLOTACIÓN DE SUS RECURSOS EN LA EDAD MEDIA FRANCISCO MARMOLEJO CANTOS

fin a las estructuras tribales que bien caracterizaron a la sociedad andalusí, fenómeno que podríamos extender a todas la poblaciones aisladas de la sierra de las Nieves, hasta entonces conformadas por comunidades relativamente pequeńas y cerradas, donde las prácticas exogámicas (entre individuos no emparentados) probablemente no debieron estar tan extendidas y tardarían en consolidarse.

En las líneas que siguen, pasamos a describir someramente los castillos y despoblados medievales del actual término municipal, todos circunscritos a la cuenca alta de Río Grande y Río Verde, poniendo especial énfasis, como paso previo a nuestras conclusiones, en las estructuras defensivas inéditas y desconocidas del núcleo urbano.

\section{Sistema defensivo de La Población}

\subsection{Visión de conjunto}

Tolox es una de las poblaciones malagueńas que mejor conserva el tejido urbano de época medieval, no solo en sus calles estrechas de trazado sinuoso, sino también en las parcelas y solares irregulares de los que surgen esas calles improvisadas. Si bien es pronto para determinar la evolución de la trama urbana, de los datos disponibles se podría caracterizar como una alquería de origen andalusí que se desarrolló a partir de su castillo, con un patrón de asentamiento definido en este periodo, aunque desconozcamos su origen por falta de actuaciones arqueológicas.

Se emplazaba en los límites del occidente malagueño a fines de la Edad Media, justo en la divisoria que separaba las tierras de Málaga, Marbella y Ronda, con una economía orientada a las grandes alquerías del valle del Guadalhorce. Su base de subsistencia se fundamentaba en la agricultura y ganadería, sobresaliendo en la producción de seda y en la cría de gusanos, con grandes posibilidades para el aprovechamiento cinegético y la apicultura 5 .

Se alza hoy sobre un cerro de escaso relieve poco antes de la confluencia de los arroyos Alfaguara y de los Caballos, tributarios de Río Grande ${ }^{6}$. De la importancia agrícola da cuenta el elevado número de bueyes censados en $1489^{7}$, pese a las evidentes dificultades en la explotación de estas tierras, no tanto por la topografía abrupta como por una estructura de propiedad fragmentada y dispersa, con cosechas deficitarias en su producción cerealista y escasa diversidad de recursos rentables ${ }^{8}$. Aun así, en periodo granadino

5 Puede comprobarse en AHPG, LP. 6800 y 6801.

6 Sobre el poblamiento rural en Río Grande, véase Fernández Ruiz, Juan y Márquez Romero, José Enrique. «Territorio y poblamiento humano en el río Grande». Baetica, 2001, vol. 23, pp. 263-294; MARmolejo Cantos, Francisco. Poblamiento andalusi en la cuenca fluvial de Río Grande (Málaga). Explotación y defensa del territorio en la Edad Media. Málaga: Asociación Arqueológica de Coín, Guadalhorce y Sierra de las Nieves, 2015.

AGS, Contaduría Mayor de Cuentas, $1^{a}$ época, Legs. 168 y 25. Véase también AGS, Expedientes de Hacienda, Leg. 12, fol. 30. Ladero Quesada, Miguel Ángel. «El duro fisco de los emires». Cuadernos de Historia, 1969, vol. 3, pp. 321-334 y Ramos Ibaseta, José Ramón. Política ganadera de los Reyes Católicos en el obispado de Málaga. Málaga: Diputación Provincial de Málaga, 1988.

8 AHPG, LP. 6800 y 6801. 
ESTRUCTURAS DE POBLAMIENTO EN TOLOX (MÁLAGA). LA OCUPACIÓN DEL TERRITORIO Y LA EXPLOTACIÓN DE SUS RECURSOS EN LA EDAD MEDIA FRANCISCO MARMOLEJO CANTOS

se convierte en una de las poblaciones más prósperas de la Garbía malagueña, capaz de absorber la expansión demográfica tan generalizada en periodo bajomedieval, fundamentalmente por disponer de sustratos roturables con recursos hídricos en sus inmediaciones; sin olvidar que hoy son nulas esas posibilidades por el agotamiento de estos?.

De aquellos flujos migratorios, se conservan numerosos indicadores en el entramado urbano -al margen de su gran arrabal, de marcado carácter residencial y plagado de huertos-; así, vemos desde adarves o callejas sin salida para dar acceso y servidumbre a las nuevas viviendas hasta numerosos cobertizos o pasadizos ocupando el dominio público. Dicho lo cual, no descartamos que el crecimiento urbano, en su origen, pueda estar relacionado con la concentración de los núcleos dispersos que desaparecen definitivamente entrado el siglo XI. De partida, no disponemos de datos demográficos para el periodo nazarí en Tolox ${ }^{10}$, solo sabemos que en 1492 lo habitaban 186 varones mudéjares ${ }^{11}$, en 1497 se alcanzan los 195 contribuyentes para el pago de las Guardas de la Costa ${ }^{12}$, en 1501 huyen todos en masa a la sierra ${ }^{13}$ y en 1509 solo conviven 75 vecinos ${ }^{14}$, dato este que otorga credibilidad a la supuesta existencia de un despoblado mudéjar en la cuenca alta de Río Verde, levantado ab initio por los vecinos que huyeron en clandestinidad ${ }^{15}$.

El perímetro de la fortaleza, sede del poder político y militar, pudo albergar en su interior la mezquita, posiblemente el único centro religioso del entramado urbano, al menos esta es la primera impresión que se extrae si seguimos la línea de amurallamiento y las curvas de nivel de mayor altitud, incluso se constata documentalmente la existencia de una vivienda morisca lindera con la iglesia y la alcazaba ${ }^{16}$. En lo tocante a la mezquita, habrá que convenir que el interior del actual campanario se asemeja a los alminares de estructura cuadrada con machón central, teniendo en cuenta también sus reducidas dimensiones en planta y alzado. No vamos a extendernos en este elemento por falta de espacio, tan solo confirmar que, a finales del siglo XvI, «la iglesia de esta villa está quemada y todo el techo de ella por el suelo, perdida la madera y teja, sin quedar más que las paredes, la cual quemaron los moriscos rebelados que andaban por la sierra» ${ }^{17}$.

9 Marmolejo Cantos, Poblamiento andalusi en la cuenca fluvial de Río Grande.

10 Tras la conquista castellana de 1485 se documentan reajustes demográficos de importancia; claro ejemplo lo encontramos en los desplazamientos masivos de los antiguos habitantes de El Burgo, que acabaron avecindados en Monda, Tolox y Casarabonela. ACM, Leg. 56, cuad. 27.

11 AGS, CMC, Leg. 25, año 1492. López de Coca Castañer, José Enrique. La tierra de Málaga a fines del siglo XV. Granada: Universidad de Granada, 1975, p. 33.

12 AGS, CMC, Leg. 25, año 1497.

13 AMM, Libro de Provisiones, II, fol. 49v. Sobre la pena impuesta por el alzamiento véase AGS, CMC, leg. 42 / RGS, LG, 150107,60.

${ }_{14}$ Correspondencia del conde de Tendilla. Vol. I (1508-1509), ed. Emilio Meneses García. Madrid: Real Academia de la Historia, 1973, Carta del primero de abril de 1509. Sobre Tolox, véase f. 497, 500, 504 , 530, 548-966.

15 Creemos haber localizado este despoblado en la cuenca alta de Río Verde, en su margen izquierda, más concretamente sobre las terrazas inmediatas al partido de Alcornocalejo, por debajo del primitivo camino de Arboto. El yacimiento en cuestión, que tenemos en proceso de estudio, ofrece la oportunidad única de estudiar el grado de aculturación de la comunidad mudéjar tras la conquista castellana, sin intromisión de otras culturas materiales.

16 AHPG, LP n. ${ }^{\circ} 6.800$, fol. 408v. Seguimos la primera foliación de esta fuente documental.

17 AHPG, LP n. ${ }^{\circ} 6.801$, fols. 9 y 19. 
ESTRUCTURAS DE POBLAMIENTO EN TOLOX (MÁLAGA). LA OCUPACIÓN DEL TERRITORIO Y LA EXPLOTACIÓN DE SUS RECURSOS EN LA EDAD MEDIA FRANCISCO MARMOLEJO CANTOS

El arrabal se desarrolló extramuros, invadiendo parte del espacio irrigado, al suroeste del núcleo fundacional e inmediato al pago de Igualeja (<Walaŷa: meandro $)^{18}$, ocupando una diagonal desde la calle Cuesta del Caño hasta la plaza Alta ${ }^{19}$. Por otra parte, la primitiva necrópolis también se localizaba extramuros, en la actual plaza Alta, aprovechando una explanada cercana a la fortaleza y la mezquita. En el callejero de la localidad aún pervive a duras penas la llamada calzada y plaza del Mocabel (<Maqābir: tumbas, cementerio $)^{20}$. Su localización y extensión podría precisarse tras el reciente hallazgo de restos óseos en el lugar donde se edificó el parking cercano al antiguo Mercado Municipal. Es posible que, tras la conquista, la necrópolis antedicha no cayera en desuso como lugar de enterramiento, al menos tenemos constancia documental que a Fernando de Angulo «diosele un sitio para mesón en Tolox cerca del honsario sy hubiere lugar, sin perjuicio y que no toque al honsario» ${ }^{21}$.

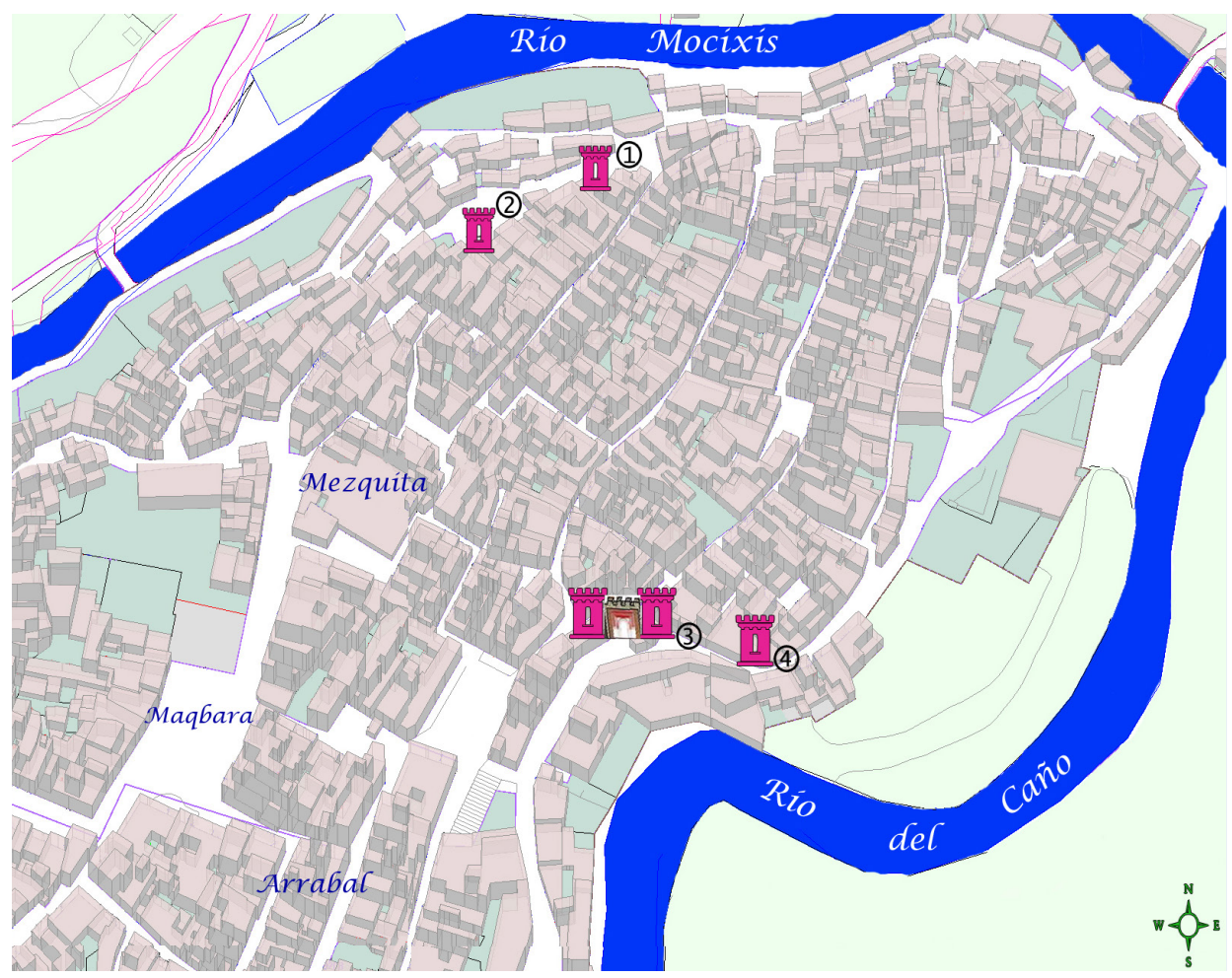

Figura 1. Plano tridimensional del actual entramado urbano; localización de las estructuras documentadas. Mapa: F. Marmolejo.

18 AHPG, LP n. ${ }^{\circ} 6.800$, fols. 348v y 499.

19 AHPG, LP n. ${ }^{\circ} 6.800$, fols. 283, 301v, 348v, 389, 391 y 499.

20 AHPG, LP, n. ${ }^{\circ} 6.800$, fol. 615v

21 AMM, Libro de Repartimiento, vol. III, fol. 203v. 
ESTRUCTURAS DE POBLAMIENTO EN TOLOX (MÁLAGA). LA OCUPACIÓN DEL TERRITORIO Y LA EXPLOTACIÓN DE SUS RECURSOS EN LA EDAD MEDIA FRANCISCO MARMOLEJO CANTOS

\subsection{Castillo y murallas}

Iniciamos la investigación arqueológica sobre las defensas de Tolox con un heterogéneo grupo de construcciones militares, algunas interrelacionadas entre sí. Centraremos nuestra atención en el castillo y recinto amurallado, sin descuidar otros elementos a extramuros, de los que no queda el menor testimonio arqueológico, tal es el caso de su casa fuerte de época mudéjar y su torre almenara, de cronología incierta.

De partida, el lugar escogido para fundar la población contaba con suficientes defensas naturales, ceñido por dos pequeños ríos, uno de ellos encajonado, y provisto con importantes tajos y desniveles, como se percibe en el Barranco de Amador o en las caídas de la plaza de la Constitución. Según iremos viendo, el aparato defensivo fue evolucionando en el tiempo, incorporando nuevos elementos arquitectónicos para reforzar sus flancos más débiles.

De la fortaleza se conservan bastantes evidencias arqueológicas, aunque en la actualidad parezca lo contrario. Creemos haber identificado algunos lienzos y torres integradas entre las viviendas, lo cual nos permite definir en gran medida el perímetro amurallado, adaptado a la topografía de la plataforma en la que se asienta, de planta irregular y tendencia alargada; aunque sin ocupar la calle Castillo en toda su extensión, en contra de lo que hoy se piensa ${ }^{22}$.

La calle Calzada de la Iglesia fue eje vital del Tolox andalusí; por la misma se accedía a la fortaleza por el flanco SO, siendo quizás la entrada de mayor importancia. Desde luego, la fachada $\mathrm{N}$ que mira al Barranco de Amador presenta mejores defensas y aprovecha su pronunciado desnivel. En dicho sector se conserva, en muchos tramos, el alzado completo de sus muros, recorriendo la curva de nivel de mayor cota y ajustándose a los márgenes de la meseta superior. Este recinto principal cerraba siguiendo la línea de la calle Castillo, hasta enlazar en línea recta con la puerta que hemos situado en la Calzada de la Iglesia. Uno de los lienzos mejor conservados pervive en el interior de una de las viviendas situadas en la calle Rinconada del Castillo, quedando como pared trasera de su patio y adentrándose en la casa contigua, para conectar con las caídas inmediatas a la portada de la iglesia. Hemos podido examinar la estructura con permiso del propietario, advirtiendo que su fábrica vuelve a ser de mampostería, calzada con algunos ripios cerámicos, hoy semiocultos por las sucesivas capas de cal.

Existen razones para poner en duda que la fortaleza mantuviera funciones de vigilancia y control del territorio, pues, atendiendo a su diseńo y emplazamiento marginal, más bien estuvo destinada, exclusivamente, a defender la plaza y su población. Negamos esta diversidad funcional, como tendremos ocasión de ver, porque Tolox nunca fue lugar de paso y todos los cerros contiguos disponen de mayor elevación, impidiendo toda vista, motivo por el cual fue necesario levantar una torre almenara que ampliara el campo visual. Aun así, como sabemos, no está de más añadir que las grandes formaciones montañosas que cierran el paso por el oeste juegan un papel trascendental en la defensa de la población.

Por lo que se observa, las nuevas viviendas se integraron en el recinto amurallado, muchas se adosaron a los muros y otras se construyeron aprovechando sus ruinas,

22 Error que se viene propagando hoy en publicaciones oficiales y seńalética turística. 
ESTRUCTURAS DE POBLAMIENTO EN TOLOX (MÁLAGA). LA OCUPACIÓN DEL TERRITORIO

recreciendo sus cimientos, lo que por fortuna ha permitido su conservación en diversos $\operatorname{tramos}^{23}$. De las evidencias que subsisten, mantenemos como hipótesis de trabajo que la fortaleza quedó reforzada por torres de planta cuadrada, mientras que la cerca pudo combinar torreones cuadrados y semicirculares, como veremos y matizaremos a continuación.

En 1485 la población de Tolox queda definitivamente incorporada a la corona de Castilla y, tres años después, pasa a formar parte de la jurisdicción territorial concedida a la ciudad de Málaga. No presentó batalla a los Reyes Católicos, acabó entregándose y capitulando tras la caída de Coín y luego de Ronda. Extraña, por tanto, que la fortaleza de Tolox necesitase urgentes reparaciones ese mismo año de 1485; incluso los Reyes Católicos llegaron a insistir con cuatro cartas, desde el mes de junio a octubre, para que enviasen maestros albañiles, peones, carpinteros y caleros; evidentemente la Guerra de Granada aún no había terminado ${ }^{24}$.

La crónica de la conquista escrita por Pulgar refiere que la tenencia de la fortaleza recayó sobre Sancho de Angulo ${ }^{25}$, quien permanecerá como alcaide hasta su fallecimiento, sucediéndole su hijo Âlvaro de Angulo ${ }^{26}$. En el estado actual de la investigación, sabemos que el castillo conservó su importancia militar hasta abril de 1498, cuando es derribado intencionadamente por orden $\mathrm{real}^{27}$, perdiendo su funcionalidad defensiva, lo cual debió alterar la configuración urbana heredada de época nazarí. No hay duda de que fue desmantelado definitivamente y en su integridad, pues poco después se mencionan solares en su interior, los cuales se otorgan por donación a particulares como Francisco de Angulo ${ }^{28}$. De los datos recabados, desde luego se acometieron obras de acondicionamiento para integrar las viviendas, sin por ello descartar tareas de demolición y expolio en algunos sectores. Ahora bien, no ocurre lo mismo en la vecina población de Monda, donde el marqués de Villena empieza a reedificar el castillo sin licencia en la segunda década del siglo $\mathrm{XVI}^{29}$.

De otro lado, el espacio amurallado se desarrolló al sur de la fortaleza envolviendo el caserío y reforzando sus defensas, con entrada principal por el SO desde el camino de Alozaina. La superficie defendida por ambos recintos pudo alcanzar una extensión aproximada de $14.000 \mathrm{~m}^{2}$; espacio que se verá desbordado con creces en época nazarí, superando las expectativas de crecimiento, dando así origen a un arrabal de carácter residencial. En el frente meridional la topografía se torna más suave, por tanto necesitada

23 Referencias documentales a casas linderas con la muralla se conservan, entre otras muchas, en AHPG, LP n. ${ }^{\circ}$ 6.800, fols. 253, 259v, 278, 324v, 333v, 482v, 489 y 518v.

24 El Tumbo de los Reyes Católicos del Concejo de Sevilla, publicado por Carriazo y Arroquia, Juan de Mata. En la frontera de Granada. Sevilla: Facultad de Filosofía y Letras, 1971, pp. 23-27, 63 y 389.

25 Pulgar, Fernando del. Crónica de los señores Reyes Católicos don Fernando y doña Isabel. Valencia: en la Imprenta de Benito Monfort, 1780, p. 254.

26 AGS, Cámara de Castilla, CED,2,2-2,14,3.

27 AGS, Contaduría del Sueldo, 2a Serie, Leg. 368, s/f. Ladero Quesada, Miguel Ángel. «La defensa de Granada a raíz de su conquista. Comienzos de un problema». Miscelánea de Estudios Árabes y Hebraicos. Sección Árabe-Islam, 1967, vol. 16, pp. 7-46, véase p. 34.

28 AMM, 494v.C-1792- 1, noviembre de 1500.

29 AGS, RGS, mayo 1514 , s/f. 
ESTRUCTURAS DE POBLAMIENTO EN TOLOX (MÁLAGA). LA OCUPACIÓN DEL TERRITORIO Y LA EXPLOTACIÓN DE SUS RECURSOS EN LA EDAD MEDIA FRANCISCO MARMOLEJO CANTOS

de otro cinturón exterior, no solo para proteger el espacio de hábitat sino también para reforzar el dispositivo. Así pues, la cerca defensiva se diseña partiendo de una fortificación previa, la alcazaba, con la que va a enlazar cerrando su perímetro al norte. Por lo que se observa, los lienzos visibles recorren en parte un afloramiento rocoso acogiendo en su interior las calles Villa Alta y Villa Baja. El aparejo que le caracteriza ha quedado oculto con el enlucido de las viviendas, lo que impide concretar la técnica edilicia, aunque a todas luces se trata de mampostería recalzada según apreciamos en la torre n. ${ }^{\circ}$ 4. A falta de un análisis más exhaustivo sobre las técnicas y materiales empleados, independientemente de su origen, los restos conservados no pueden llevarse más allá del periodo almohade-nazarín ${ }^{30}$.

De ambos recintos hemos logrado identificar cuatro estructuras de torre que hemos numerado y localizado en el plano que ilustra el texto. Se caracterizan por sobresalir del plano de fachada, todas cubiertas con terrados y cimentadas sobre la roca natural, recreciendo las curvas de nivel de mayor altitud y abriendo escasos vanos al exterior.

\section{Torre n. ${ }^{\circ} 1$}

Situada en el sector norte del recinto, mirando al Barranco de Amador, aún permanece en pie una estructura con aspecto de torre, semioculta entre las edificaciones modernas, lo que dificulta y empaña su lectura arqueológica. De partida, no podemos descartar que se encuentre macizada, motivo por el cual no ha llegado a integrarse en ninguna vivienda. Se destacaba del recinto, según testimonios gráficos, proyectándose al exterior y adelantándose con respecto a la línea de muralla, sin que por ello la tengamos por albarrana. Su estado actual permite precisar su arquitectura original, al conservarse prácticamente intacta y no estar habitada. Su fábrica presenta mampuestos irregulares de mediano tamaño, con un llagueado exterior a modo de vitola que bordea sus piedras dejándolas a la vista (rejuntado), técnica de acabado frecuente en la Edad Media.

La estructura presenta un estado ruinoso, quedando expuesta a la intemperie y sin la adecuada evacuación de aguas pluviales, lo que hace peligrar seriamente su estabilidad. En la parte inferior ha perdido el mortero de agarre, dejando ver algunos ripios de pequeño tamaño para calzar la mampostería. Al exterior muestra mampuestos de variada modulación con hiladas muy irregulares, quizá reforzando una fábrica de tapial interna que creemos percibir en el tercio superior, aunque por la altura donde se encuentra no podemos asegurarlo.

30 Similar cronología se documenta en el cercano castillo de Monda, levantado de nueva planta en el siglo XII con canteros y alarifes especializados, enviados por el Estado, posiblemente para defensa y protección de campesinos y labriegos, al igual que ocurre en muchos castillos del levante peninsular. Véase AzUAR Ruiz, Rafael. "Campesinos fortificados frente a conquistadores feudales en los valles del Vinalopó». En Jover Maestre, Francisco Javier y Navarro Poveda, Concepción (coords.). De la Medina a la Vila. II Jornadas de Arqueologia Medieval. Alicante: Museo Arqueológico de Alicante, 2004, pp. 263-291. 


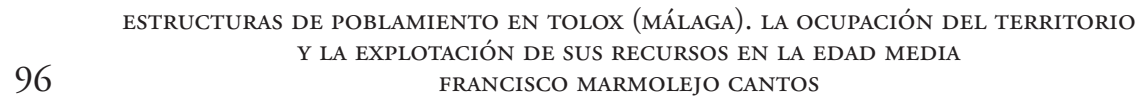

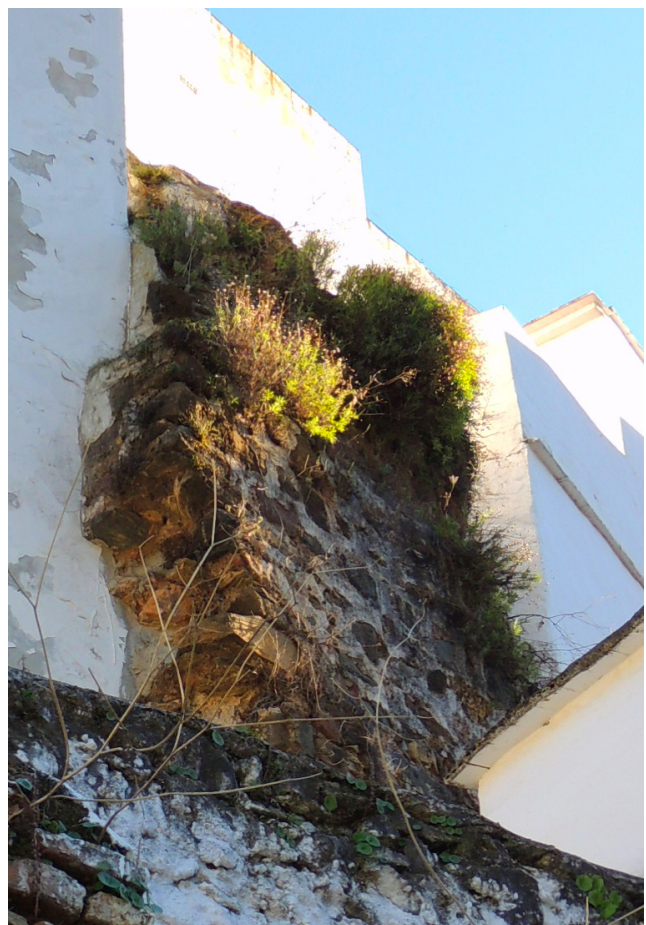

Figura 2. Aspecto actual de la estructura n. ${ }^{\circ} 1$ aprovechando el desnivel del Barranco de Amador.
Torre n. ${ }^{\circ} 2$

Se alza también defendiendo el flanco norte, sobre las caídas del Barranco de Amador, enlazando directamente con la torre que hemos descrito con el n. ${ }^{\circ} 1$, ambas separadas unos 34 metros. $\mathrm{Su}$ situación y orientación nos hace creer que pudo cerrar el perímetro del recinto, ocupando el ángulo nororiental y sirviendo de unión entre lienzos, pues, de no ser así, la línea amurallada desciende a curvas de nivel de menor cota.

Su interior se encuentra acondicionado para habitación, formando parte del fondo de una vivienda con entrada por calle Castillo. El revestimiento que cubre la fábrica original impide precisar los materiales empleados y la técnica constructiva. De lo poco que se distingue, conserva una orientación sensiblemente en dirección NO-SE, se apoya sobre el afloramiento de roca natural y sobresale con respecto al plano de muralla, siguiendo la misma línea que recorre el recinto desde la antigua mezquita.

Torre n. ${ }^{\circ} 3$

Creemos haber localizado la puerta principal de ingreso al recinto amurallado, con claros indicios de estar flanqueada por al menos una torre de planta cuadrada y posible entrada en rampa al final del camino de Alozaina. La puerta real de la Villa comunicaba los principales caminos de acceso al centro de la población y constituía el punto principal de ingreso al interior. Dicha entrada pudo disponerse en recodo entrando por el camino de Alozaina según el trazado actual de las calles que allí convergen. A nuestro entender, es de esperar que este acceso no solo fuera desde Alozaina, tal refleja la toponimia, sino también desde Coín, Monda y Guaro por el sureste, desde Yunquera y El Burgo por el noreste e incluso desde Istán, Arboto y Parauta por el oeste, cuyos caminos enlazarían todos para ingresar por esta puerta en periodo bajomedieval. Dicho lo cual, no descartamos otro posible acceso al recinto superior por el norte, de carácter secundario, en la actual calle del Portillejo.

Lo que hemos denominado torre n. ${ }^{\circ} 3$ podría formar parte de la estructura de la puerta principal, pues precisamente se eleva en el marco abierto que conecta la calle 
ESTRUCTURAS DE POBLAMIENTO EN TOLOX (MÁLAGA). LA OCUPACIÓN DEL TERRITORIO

Y LA EXPLOTACIÓN DE SUS RECURSOS EN LA EDAD MEDIA

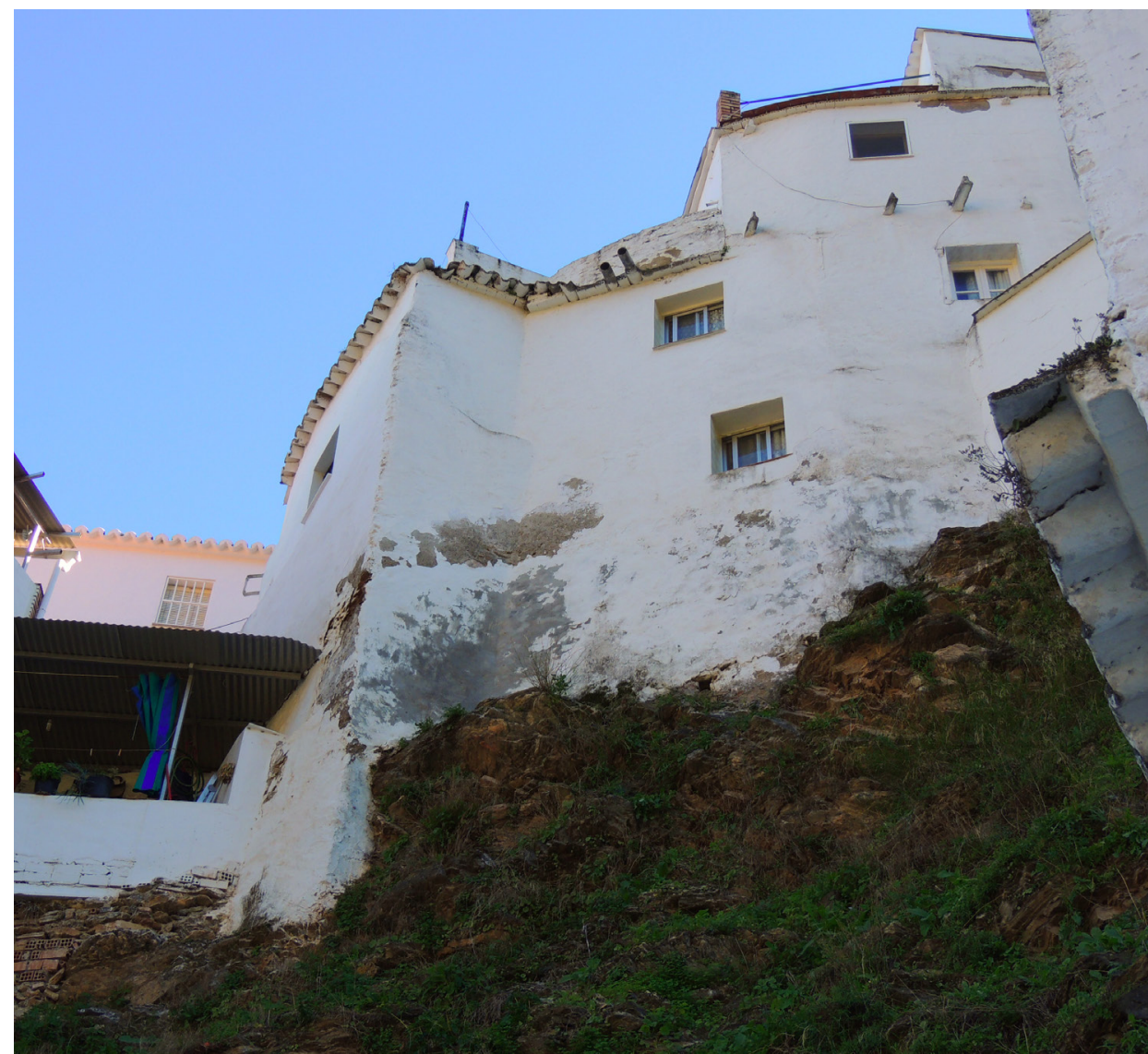

FIGURA 3.- Alzado de la estructura n. ${ }^{\circ}$ 2, hoy integrada en una vivienda con entrada por la calle Castillo.

Villa Baja con la de Alozaina. Siguiendo esta línea de argumentación, la documentación histórica insiste en que la muralla se desarrollaba y subía por la antigua calle Real, que comprendía la actual calle Alozaina con dirección a la Calzada de la Iglesia, donde confluía con la otra calle Real a la altura de la torre-campanario ${ }^{31}$.

En la actualidad la estructura forma parte de una vivienda habitada, en consonancia con los libros de poblamiento (s. XVI), que documentan una cámara «que está por cobertizo de la Puerta de la Villa» ${ }^{32}$. Por el momento, no podemos asegurar que dicha vivienda se corresponda con la primitiva estructura, siendo fundamental un análisis estratigráfico de sus paramentos, pero en caso contrario, a nadie escapa que la actual edificación respeta el trazado y perímetro del solar resultante.

31 AHPG, LP n. ${ }^{\circ}$ 6.800, fols. 345v-346 y 563

32 AHPG, LP n. ${ }^{\circ} 6.800$, fol. $515 \mathrm{v}$. 
Torre n. ${ }^{\circ} 4$

FRANCISCO MARMOLEJO CANTOS

Nos hallamos ante una estructura de planta semicircular, única de este género que hemos documentado en la población; para nuestro asombro todavía inédita y desconocida, pese a su singular aspecto exterior y su localización. Se alza sobre un afloramiento de roca natural en la parte alta de la calle Alozaina, cubierta por un terrado y sin abrir vanos al exterior, a unos 35 metros de lo que hemos caracterizado como Puerta de la Villa. De este indicio, se podría trabajar con la hipótesis de que la cerca tal vez pudo alternar torres cilíndricas y cuadradas, aunque desconocemos la tipología y distribución original del resto de torres, hoy perdidas por el lienzo meridional. La identificación del aparejo se

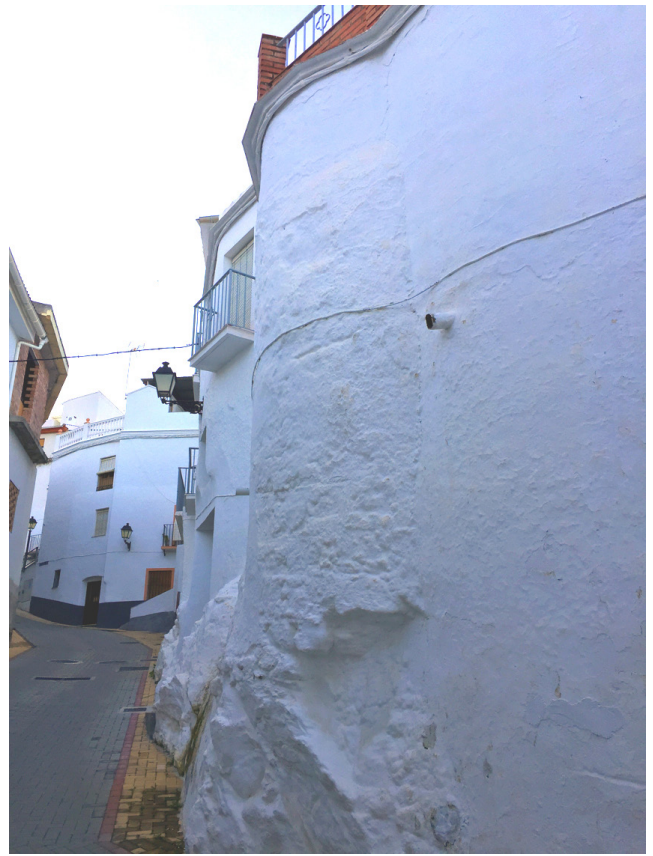

Figura 4. Vista de la estructura semicircular situada en la calle Alozaina. complica al estar enlucida parcialmente y solo es perceptible en su base, donde se observan mampuestos desordenados de diferente modulación, algunos enripiados, conformando hiladas muy irregulares.

En la actualidad, la estructura se encuentra también habitada formando parte de una vivienda de la calle Alozaina, fenómeno que se constata documentalmente en muchas ocasiones a finales del siglo XVI, valga de ejemplo la referencia a una casa "que alinda con un muro e con la calle Real, e no entra en esta morada la dicha torrecilla porque es de otro poblador ${ }^{33}$. Si bien la vivienda que hoy ocupa la torre n. ${ }^{\circ}$ 4 presenta una entrada lateralizada de marcado carácter defensivo, a la cual se accede mediante un estrechísimo adarve que le sirve de servidumbre. En lo que a nosotros interesa, llama la atención que no tenga acceso directo por su fachada principal a la calle, lo que hubiera hecho innecesaria la apertura de dicho adarve.

\subsection{Casa fuerte y torre almenara}

Sin ánimo de alargar nuestra exposición, dejaremos constancia de la existencia de otro elemento fundamental en el complejo defensivo, tal es el caso de la casa fuerte que los vecinos mudéjares levantaron extramuros a principios del siglo xvi. Su origen

33 AHPG, LP n. ${ }^{\circ}$ 6.800, fol. 333v. 
ESTRUCTURAS DE POBLAMIENTO EN TOLOX (MÁLAGA). LA OCUPACIÓN DEL TERRITORIO Y LA EXPLOTACIÓN DE SUS RECURSOS EN LA EDAD MEDIA FRANCISCO MARMOLEJO CANTOS

quizá haya que buscarlo en la necesidad de reestructurar el aparato defensivo, precisamente con la instalación de un nuevo elemento que supliera la merma sufrida en 1498, cuando se ordenó el derribo de la fortaleza ${ }^{34}$. Sabemos de su existencia y localización por el dibujo que obra en el catastro de Ensenada, en el que se muestra una casa con dos torres de flanqueo a ambos lados, aunque una de ellas se representa separada del inmueble ${ }^{35}$. Se ubicaba en la plaza principal de la villa, próxima a la desaparecida ermita de los santos patronos,



FiguRA 5. Situación geográfica de los asentamientos documentados en término de Tolox: 1. Castillo de Tolox; 2. Fortaleza de la Teja; 3. Castillo de Cerro Corona; 4. Despoblado de Murta; 5. Necrópolis de Lobato; 6. Despoblado de Robaquel; 7. Llanos del Tejar; 8. Llanillos del Piloncillo; 9. Despoblado del Moralejo; 10. Villares de Boliges; 11. Ardite. Mapa: F. Marmolejo.

San Sebastián y San Roque, de la que se conservan diversos testimonios gráficos del siglo xx. De las referencias históricas disponibles, todo parece indicar que se construyó con mano de obra mudéjar a impulsos del marqués de Villena y se financió, en parte, con la venta de la bellota de los montes comunales, sirviendo de pósito, cárcel y audiencia ${ }^{36}$.

En el plano de Ensenada se aprecia también otra construcción de carácter defensivo, plenamente integrada en el dispositivo de alerta y vigilancia diseñado para la población ${ }^{37}$. Se trata de una torre almenara de excelentes condiciones geoestratégicas, con la clara función de ampliar el campo visual hacia el noroeste ${ }^{38}$. No hay datos certeros en cuanto a su origen y localización exacta, pero todo apunta a que pudo ubicarse en los cerros contiguos a la actual Vía Sacra, al norte de la población, en un lugar elevado por encima del caserío. A falta de testimonios arqueológicos, no podemos garantizar su existencia en

34 AGS, Contaduría del Sueldo, 2a Serie, Leg. 368, s/f. Ladero Quesada, La defensa de Granada a raiz de su conquista, p. 34.

35 AHPG, Catastro de Ensenada, población de Tolox y AGS, CE, RG, L. 302. Véase SÁnchez GueRRA, Diego J. «Tolox en un dibujo de mediados del siglo xviII del Catastro de Ensenada», 2013, http:// airesdemonda.blogspot.com.es/2013/10/tolox-en-un-dibujo-de-mediados-del.html.

36 AHPG, LP n. ${ }^{\circ}$ 6.800, fol. 2v. Sobre la construcción de la Casa Fuerte de Monda véase AHN, FRIAS, C. 717, D.49 y AGS, C.a C.a, Leg. 2213, s/f, donde la titularidad del inmueble se adjudica a la Corona, tal vez por error. Más datos en SÁNchez Guerra, Diego J. «El Bombo y la casa fuerte del marqués de Villena. Un paseo por la historia y la memoria de Monda», 2016, https://goo.gl/YLyveW.

37 AHPG, Catastro de Ensenada, población de Tolox y AGS, CE, RG, L. 302. Véase SÁnchez GueRRA, «Tolox en un dibujo de mediados del siglo XVIII del Catastro de Ensenada».

38 A nuestro entender, para este tipo de estructuras tan cercanas y vinculadas a núcleos de población, no tenemos tan claro que formara parte de una red de torres vigías, únicamente podríamos argumentar que estuvieron destinadas a transmitir el peligro al caserío anejo. 
ESTRUCTURAS DE POBLAMIENTO EN TOLOX (MÁLAGA). LA OCUPACIÓN DEL TERRITORIO Y LA EXPLOTACIÓN DE SUS RECURSOS EN LA EDAD MEDIA FRANCISCO MARMOLEJO CANTOS

época andalusí, aunque su papel como vigía es fundamental de cara a prevenir cualquier amenaza o peligro que lograra atravesar Río Grande.

\section{Fortaleza de la Teja}

Sobre la misma tuvimos ocasión de publicar un artículo de carácter divulgativo, al que nos remitimos por falta de espacio en esta ocasión ${ }^{39}$. Se eleva sobrepasando los mil metros de altura en la divisoria entre los términos de Monda y Tolox, dominando estratégicamente todo el valle del Guadalhorce hasta alcanzar la bahía de Málaga. El recinto principal dispone de planta rectangular de aproximadamente $20 \times 62 \mathrm{~m}$, con orientación N-S. En su fábrica emplea mampuestos y sillarejos de fractura extraídos a pie de obra, trabados con una argamasa carente de cal. Su interior se muestra compartimentado por un muro divisorio hacia el centro del rectángulo, similar en planta al observado en los Castillejos de Ronda (junto a Sierra Hidalga).

En la fachada $\mathrm{N}$ se evidencian las zapatas de cimentación de dos torres de planta cuadrada, con unos dos metros de lado. En los frentes oeste y sur, envolviendo parcialmente el recinto principal, se aprecian los cimientos de otro gran lienzo de muralla, fabricado con mampuestos, esta vez empleando abundante cal en el mortero. Este amurallamiento exterior describe un perímetro irregular y se pierde por el flanco NE, siendo aquí innecesario por el acusado desnivel. La superficie que queda entre ambos recintos es tan reducida que apenas deja espacio libre para el establecimiento de viviendas. En una visión de conjunto, sus dimensiones totales se alejan mucho de las grandes fortalezas de la frontera marítima (Cańas, Ojenete, Torrón, Montemayor, Nicio) todas situadas en las altas cumbres de las sierras litorales occidentales. Si bien el volumen de población que albergan las alquerías de la sierra de las Nieves es muy superior al que detectamos en el litoral y el valle.

La fortaleza objeto de estudio aparece citada en los apeos de Monda (siglo XvI) como Hasnalmenqueire (Hișn al-Menqueire) ${ }^{40}$, topónimo que da cuenta de su condición defensiva en altura y en el que se advierte el sufijo -eire, de origen romance. De ser correcta la grafía que nos ha llegado, el topónimo constituye una clara excepción a las diferencias terminológicas propuestas por Acién Almansa entre el valle del Guadalquivir, donde se ubican ciertas poblaciones con topónimos en Azn- (Aznalcázar, Aznalcóllar, etc.), y el arco montañoso que lo envuelve, donde son frecuentes los topónimos en Izn(Iznájar, Iznalloz, etc. $)^{41}$.

En el interior de ambos recintos aparecen conjuntos cerámicos de tradición tardoantigua y emiral, junto a otras producciones características del periodo califal. Son

39 Marmolejo Cantos y Sánchez Guerra, «La fortaleza de la Teja y la alquería de Gaimón».

40 Ibídem. Sobre la identificación de esta fortaleza con el hiṣn al-Menqueire citado en el libro de Apeo de Monda, véase Marmolejo Cantos, Francisco. Históricas y arqueológicas del Medievo en Coín. Málaga: edición digital, 2009, p. 216.

41 Acién Almansa, Manuel. «La islamización del SE de al-Andalus. Los datos arqueológicos». En Boldrini, Enrica y Francovich, Riccardo (eds.). Acculturazione e mutamenti. Prospettive nell'Archeologia Medievale del Mediterraneo. Firenze: All'Insegna del Giglio, 1995, pp. 13-28. 
ESTRUCTURAS DE POBLAMIENTO EN TOLOX (MÁLAGA). LA OCUPACIÓN DEL TERRITORIO Y LA EXPLOTACIÓN DE SUS RECURSOS EN LA EDAD MEDIA FRANCISCO MARMOLEJO CANTOS

frecuentes las tejas digitadas con meandros y las tinajas a torneta con cordones digitados bajo el borde, además de las características cerámicas a mano de pasta gruesa y abundantes desgrasantes ${ }^{42}$. Entre los ejemplares que permiten su datación destacamos la existencia de marmitas de bordes reentrantes y candiles de piquera corta, propios de contextos emirales. Subrayamos también la ausencia de vedrío en ataifores de paredes curvas y el predominio de vasijas de almacenamiento (jarras y tinajas). Como señalábamos, los vidriados altomedievales apenas están representados en niveles superficiales, tan solo hemos advertido un fragmento aislado de ataifor melado con trazos de manganeso. El acabado de las piezas se suele reducir a simples alisados, si bien algunas presentan decoración realizada a peine formando meandros y otras, con reticulado inciso al exterior, de amplia cronología, con perfiles que pueden corresponder a jarritas o jarros de tipología islámica.

El modelo de asentamiento responde al complejo hișn-qarya tan generalizado en al-Andalus ${ }^{43}$, en tanto que la fortaleza ejerce influencia directa sobre tres alquerías de considerables dimensiones: Gaimón, Moratán y Chiribenítez, dos de ellas documentadas arqueológicamente ${ }^{44}$. En sus espacios de trabajo se percibe una agricultura apenas tecnificada, vinculada a surgencias naturales, aprovechando las pequeñas terrazas de los arroyos encajonados que fluyen hacia Río Grande, lo que podríamos calificar de un sistema agrario autosuficiente. La zona se configura como área óptima para el ganado a la luz de la documentación histórica, además de las majadas y pilares que se conservan; de hecho su territorio se ve atravesado por la extensa cañada Real del Mojón de Puerto Verde ${ }^{45}$, que soslaya, por los puertos de Ojén y de los Pescadores, el cordón montañoso de las sierras litorales para acceder al Val de Çuer, donde nos dice el sabio polígrafo Ibn al-Jațîb que se hallaban «los pastos que alimentan a los ganados del patrimonio real, y los pastores que cuidan de estos ganados son la gente más salvaje que existe en el mundo» ${ }^{46}$. No disponemos de datos sobre la Alta Edad Media; pero en sentido estricto el sistema ganadero de época nazarí no dejaba de ser marginal en la zona, basado en pequeñas explotaciones y representado tan solo por el sector ovino y especialmente caprino ${ }^{47}$.

42 Alba Calzado, Miguel A. y Gutiérrez Lloret, Sonia. «Las producciones de transición al Mundo Islámico: el problema de la cerámica paleoandalusí (siglos viII y ix)». En Bernal CaSASOLA, Darío y Ribera i Lacomba, Albert (eds.). Cerámicas hispanorromanas. Un estado de la cuestión. Cádiz: Universidad de Cádiz, 2006, pp. 585-613.

${ }_{43}$ Similar forma de poblamiento podemos apreciar en las poblaciones modernas de Yunquera y Ojén, ambas fueron alquerías medievales situadas a media ladera, cuyo origen desconocemos por falta de actuaciones arqueológicas, aunque sabemos que estuvieron dominadas por primitivos castillos desde las cumbres de los cerros inmediatos (Fortalezas de Ojenete y Labrados).

44 Marmolejo Cantos y Sánchez Guerra, «La fortaleza de la Teja y la alquería de Gaimón». Debo el conocimiento de la alquería de Moratán a Diego J. Sánchez Guerra, a quien agradezco sus indicaciones.

45 Ibidem. Marmolejo Cantos, Francisco. El castillo de Benamaquis. Limites y localización histórica. Coín: edición digital, 2014.

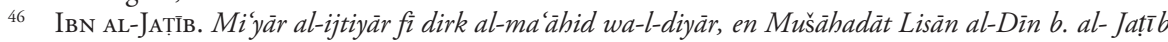
fì biläd al-Magrid wa-l-Andalus (Maymǘa min rasāỉla-hu). Ed. Aḥmad Mujtār al-'Abbādī. Alejandría, 1983, trad. Mohammed Kamal Chabana, Marruecos, 1977, p. 116.

47 AGS, Contaduría Mayor de Cuentas, $1^{a}$ época, Legs. 168 y 25. Véase también AGS, Expedientes de Hacienda, Leg. 12, fol. 30. Ladero Quesada, «El duro fisco de los emires», pp. 327-334 y Ramos IBaseTA, Política ganadera de los Reyes Católicos en el obispado de Málaga. 
ESTRUCTURAS DE POBLAMIENTO EN TOLOX (MÁLAGA). LA OCUPACIÓN DEL TERRITORIO Y LA EXPLOTACIÓN DE SUS RECURSOS EN LA EDAD MEDIA

\section{Castillo de Cerro Corona}

Estamos ante un reducto de pequeñas proporciones de cronología altomedieval, atendiendo al registro arqueológico perceptible en un contexto superficial. Se alza sobre una cota de $1.299 \mathrm{msnm}$, en un cerro elevado a los pies de la sierra de las Nieves, con importantes defensas naturales en todas sus vertientes y amplio dominio visual. Su función estratégica es incuestionable, dada su privilegiada situación, manteniendo contacto con casi todas las fortalezas altomedievales de la comarca ${ }^{48}$. Sus pequeñas dimensiones permiten caracterizarlo como fortín con claras funciones militares, idóneo para albergar una reducida guarnición, similar en tamaño a los existentes en el puerto del Viento y cerro de Ardite (TM de Alozaina) ${ }^{49}$, sin duda para control y vigilancia del territorio circundante, y en especial sobre los puertos de Corona y Golondrinas.

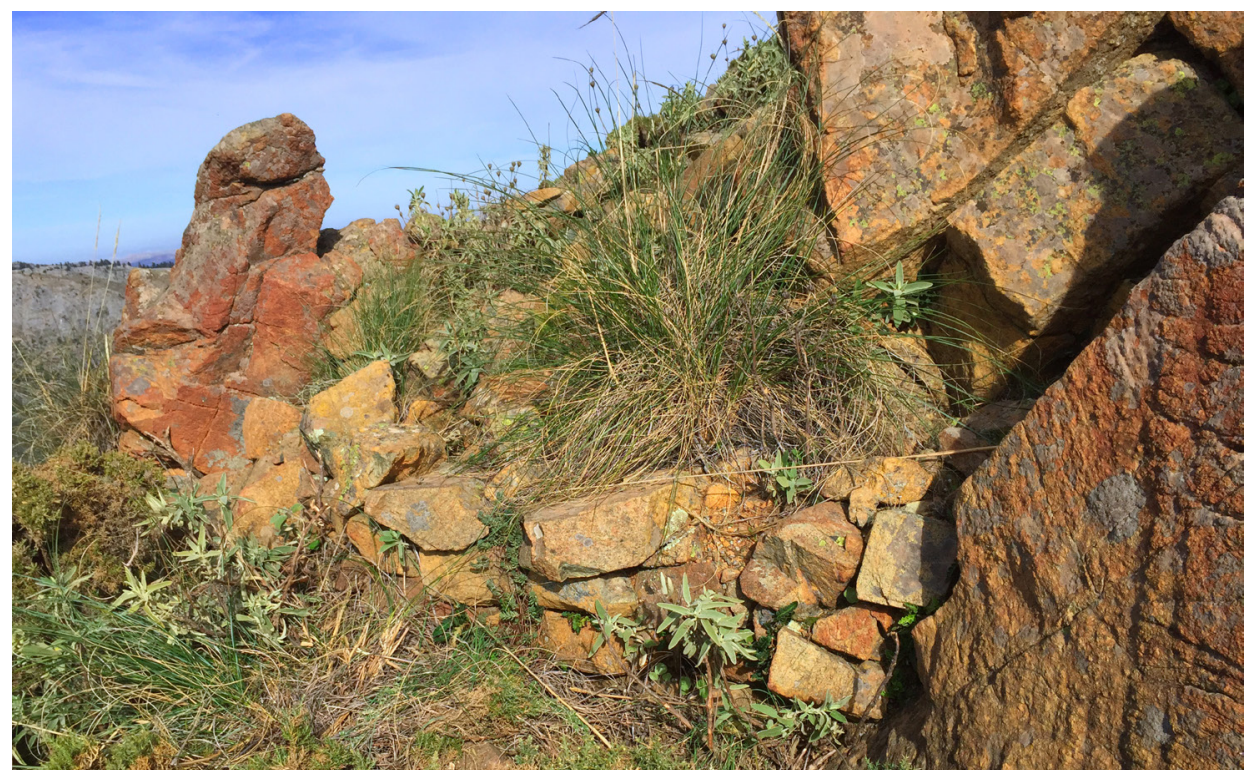

Figura 6. Primeras hiladas del recinto exterior que bordea la cumbre del cerro.

En Cerro Corona conocíamos la existencia de un asentamiento en altura, según informes de Pedro Ximénez, médico de Tolox en el siglo XviII ${ }^{50}$, y recientes trabajos

48 Marmolejo Cantos, Poblamiento andalusi en la cuenca fluvial de Río Grande (Málaga). Del mismo autor: La Edad Media en Coín y su alfoz. Coín: Asociación Arqueológica y Excmo. Ayuntamiento, 2014.

49 Sobre el castillo de Ardite véase Marmolejo Cantos, Francisco. «La alquería bajomedieval de los Padules. La evolución de un deire consagrado a Santo Bítar». Debates de Arqueología Medieval, 2014, vol. 4, pp. 111-129.

50 Ximénez, Pedro. «Informe sobre Tolox». En Suplemento al Diccionario Geográfico Malacitano de Medina Conde, original conservado en el Archivo Municipal de Málaga, Manuscrito Fondo Antiguo, BM 3/129, fols. 201-241. 
ESTRUCTURAS DE POBLAMIENTO EN TOLOX (MÁLAGA). LA OCUPACIÓN DEL TERRITORIO Y LA EXPLOTACIÓN DE SUS RECURSOS EN LA EDAD MEDIA FRANCISCO MARMOLEJO CANTOS

publicados por Acién Almansa. Sin embargo, estamos en condiciones de asegurar que no estamos ante un hisn-refugio de poblamiento, como se ha dicho, sino ante un reducto fortificado de carácter militar, con aljibe y torre central en su cota máxima, al que se ańade un recinto exterior de perímetro irregular cerrando el complejo. En la meseta superior se perciben algunas hiladas a ras de suelo empleando mampuestos fracturados de peridotitas. De igual modo, se aprecian importantes derrumbes en su caída NO y algunos muros emergentes, de casi medio metro, bordeando la corona del cerro en sus extremos $\mathrm{S}$ y $\mathrm{O}$.

Indicadores de su exclusiva función militar no solo cabe apreciar en sus excelentes condiciones geoestratégicas, sino tanto o más como lugar indeseable y repulsivo para el establecimiento humano, teniendo en cuenta el reducido espacio de su cumbre y las duras condiciones de altura, con fuertes vientos y precipitaciones níveas en los meses invernales. De partida, sus defensas naturales alcanzan casi el $80 \%$ de pendiente a medida que nos aproximamos a las cotas máximas. Con todo lo expuesto, salvo mejor criterio, se comprende que no haya núcleo de población asociado en sus proximidades.

Los conjuntos cerámicos presentan tecnología y tipología similar a los observados en la fortaleza de la Teja, con mayor presencia de vidriados altomedievales, junto a otras producciones propias de contextos emirales ${ }^{51}$. La serie ataifor está presente con diversidad de melados, algunos monocromos y otros decorados con manganeso. Entre el material arqueológico asociado al reducto, nuevamente se aprecian fragmentos cerámicos decorados con cordones con impresiones, pertenecientes a tinajas y anafes, además de algunos ejemplares de jarritas o jarros decorados con reticulado inciso al exterior. Por lo demás, se constata una ausencia casi total de tejas, lo cual contrasta con el registro arqueológico que vimos en la cercana fortaleza de la Teja ${ }^{52}$.

\section{Despoblado de Murta}

Nos hallamos ante el despoblado altomedieval de mayores dimensiones que hemos documentado dentro de los límites municipales. Se ubica inmediato a la majada de Murta, al pie del camino de Sierra Blanquilla y no lejos de la fuente de Janón ${ }^{53}$. Ocupa una pequeña explanada abierta en un cerrillo en parte aterrazado, situado a una altura nada despreciable, aunque adolece de defensas naturales de importancia.

El topónimo Murta ( $<$ Myrtus: mirto, arrayán) aparece con relativa frecuencia en la documentación de Tolox de los siglos XV al XviII; aunque en nuestros días ha desaparecido por completo todo rastro, tan solo lo encontramos en la cartografía del catastro histórico, en una parcela aislada nombrada «majada de Multa» ${ }^{54}$.

51 Alba Calzado y Gutiérrez Lloret, «Las producciones de transición al Mundo Islámico», pp. 585-613.

52 Marmolejo Cantos y Sánchez Guerra, «La fortaleza de la Teja y la alquería de Gaimón». De los mismos autores véase: «Porticate, alquería altomedieval y centro siderúrgico en la Sierra de las Nieves (Málaga)». Revista del Centro de Estudios Históricos del Reino de Granada, 2014, vol. 26, pp. 33-51.

53 Ibidem.

54 AHPM, Trabajos Topográficos Catastrales, provincia de Málaga, término municipal de Tolox. 
ESTRUCTURAS DE POBLAMIENTO EN TOLOX (MÁLAGA). LA OCUPACIÓN DEL TERRITORIO Y LA EXPLOTACIÓN DE SUS RECURSOS EN LA EDAD MEDIA FRANCISCO MARMOLEJO CANTOS

El espacio de hábitat, hoy prácticamente intacto, integra unidades de viviendas aisladas, separadas entre 5 y 8 metros unas de otras, con diferentes agrupaciones dispersas por el yacimiento, atendiendo a los restos perceptibles tras el hundimiento de los tejados. Entre el material cerámico vinculado a estos hogares aparecen, con densidad, los característicos ataifores melados de los siglos X Y XI, sin existir vestigios de época bajomedieval. En gran proporción se evidencian tejas decoradas con meandros y ataifores vidriados monocromos, predominando los melados en diversas tonalidades, entre grandes vasijas contenedoras como jarras y tinajas, estas últimas distinguibles por los característicos cordones digitados.

La lectura que podamos hacer del territorio se ve dificultada en nuestros días por la deforestación, así como por las roturaciones que propiciaron los pequeños caserones y cortijos de montaña del Gatuz, Janón y Murta. Los recursos económicos susceptibles de explotación tienen reflejo en los vestigios de majadas, caleras y eras de labor, junto a las pequeñas albarradillas que evidencian la puesta en viñedo. Desde luego las comunidades campesinas no encuentran aquí grandes posibilidades agrícolas. Son suelos pobres, poco desarrollados y apartados de los grandes sistemas de captación fluvial, con la salvedad del uso agrícola que pudo darse en las terrazas de la Alfaguara. Ahora bien, los recursos hídricos no son nada despreciables en términos cuantitativos, aunque muy limitados hoy por el escaso caudal y la sequía estival, aspecto en el que volveremos a incidir. Por lo demás, las pequeñas y dispersas superficies destinadas a tierras de pan estuvieron exclusivamente vinculadas a la subsistencia familiar, nada rentables, con cosechas deficitarias y de escasa calidad.

La zona quedó destinada tradicionalmente al aprovechamiento silvopastoril, no solo para herbaje de las pequeñas explotaciones ganaderas de montańa, sino también como zona de trashumancia de corto recorrido hacia los pastos de la llamada «Sierra Nevada de Tolox $\aleph^{55}$. La elevada cantidad de fuentes que por entonces existían ${ }^{56}$, hoy desaparecidas o muy mermadas, hacían posible los pastos de verano, únicos en toda la tierra de Málaga, pues el deshielo tenía lugar precisamente a comienzos de esa estación. Respalda nuestra hipótesis el hecho de que Río Grande, «al contrario de todos los otros ríos, en invierno es pequeño, y no lleva mucha agua, y pasado el mes de mayo, entrando las calores, comienza a crecer, y va todo el estío muy poderoso y acrecentado sin poderse vadear ${ }^{57}$.

\section{Necrópolis del partido de Lobato}

Justo en la divisoria que parte términos entre Tolox y Guaro, en los confines del partido rural de Lobato, se halló hace años una necrópolis, de cronología incierta, con

55 ACM, Leg. 56, cuadrante 38, o bien consúltese AMM, Libro de Actas Capitulares, vol. 1, fols. 99 y ss. Véase López de Coca Castañer, La tierra de Málaga a fines del siglo XV.

56 XiméneZ, «Informe sobre Tolox», fols. 201-241.

57 Morales, Ambrosio de. Las antigüedades de las ciudades de España. Madrid: en la Oficina de Don Benito Cano, 1792, vol. IX, pp. 172-173. Nos dice: «Las sierras muy altas llamadas de Tolox, que están por ambas riberas deste río, tienen unas grandes hoyas y muy hondas por lo alto (...) en el invierno se hinchan todas de nieve; y con la frialdad de aquellas alturas se hiela, y dura cuajada hasta el verano. Entonces ya el calor la comienza a derretir, y no teniendo salida el agua, y siendo la sierra de cascajo abierto, cuélase el agua hasta lo baxo, y así corresponde a la corriente del río, y hace aquel tan grande acrecentamiento». 
ESTRUCTURAS DE POBLAMIENTO EN TOLOX (MÁLAGA). LA OCUPACIÓN DEL TERRITORIO

Y LA EXPLOTACIÓN DE SUS RECURSOS EN LA EDAD MEDIA

FRANCISCO MARMOLEJO CANTOS

ocasión del ensanche de un camino forestal. Se descubrieron unas siete estructuras sepulcrales con losas de pequeño grosor y orientación diversa, sin por ello descartar la existencia de otras muchas bajo el subsuelo. En los movimientos de tierra, se hallaron algunos elementos metálicos como depósito funerario, más concretamente unos aretes de cobre que damos hoy por desaparecidos.

El sistema constructivo empleado en los sepulcros consiste en la excavación de una fosa en tierra y su delimitación con lajas dispuestas en vertical, con la salvedad de una de las estructuras, que solo conserva la losa de cubierta reposando sobre la fosa. Las lajas laterales disponen de un grosor aproximado de 3 y $7 \mathrm{~cm}$, exactamente igual que las losas de cubierta, que por su parte están calzadas para su nivelación, con una media de $70 \mathrm{~cm}$ de largo por 60 de ancho.

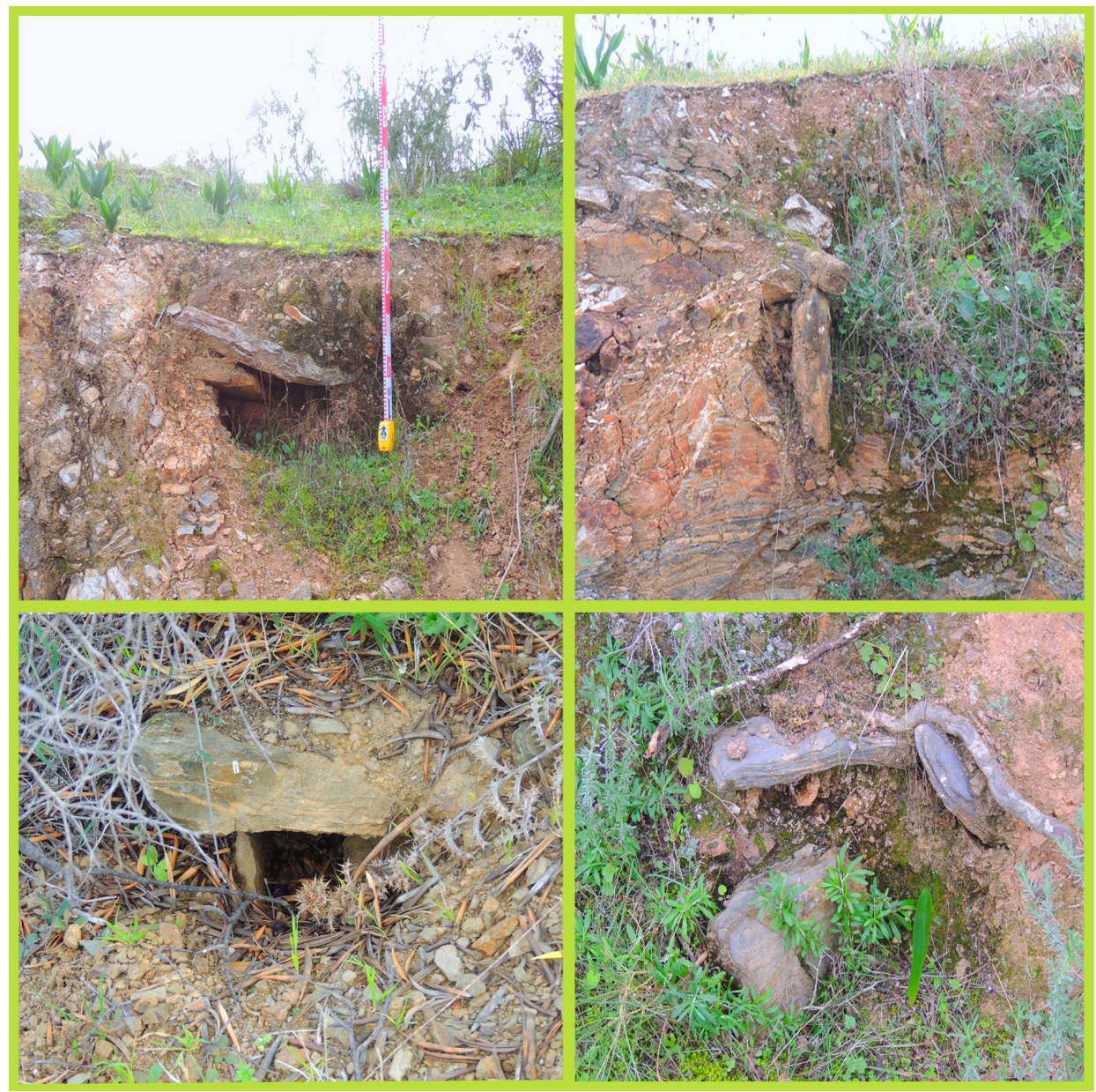

Figura 7. Estructuras de enterramiento en los perfiles abiertos por el camino forestal. 
ESTRUCTURAS DE POBLAMIENTO EN TOLOX (MÁLAGA). LA OCUPACIÓN DEL TERRITORIO Y LA EXPLOTACIÓN DE SUS RECURSOS EN LA EDAD MEDIA FRANCISCO MARMOLEJO CANTOS

A falta de actuación arqueológica que permita exhumar los sepulcros, todo apunta a que estas prácticas de enterramiento son de tradición islámica, según comparación tipológica, aunque algunas estructuras guardan orientación NW-SE, conforme a la práctica cristiana, tal vez por empuje de las raíces. De partida, el grosor de las lajas y en especial la anchura de las fosas se apartan de las características inhumaciones con losas verticales de tipología romana y tardoantigua, por el contrario el depósito funerario hallado resulta extraño al ritual islámico.

Se ignora la localización exacta del espacio de hábitat asociado a esta necrópolis, aunque en la caída meridional del cerro se observan algunos restos de cerámica espaciada, de difícil datación por lo reducido de la muestra. Dicho lo cual, no pasaremos por alto que, en documentación histórica, aparece el topónimo Quiniçia (<Kanisa: iglesia cristiana) en un pago rural próximo al arroyo Estepera y al término de Guaro ${ }^{58}$, que bien podría corresponderse con este enclave, lo cual explicaría la diferente orientación que mantienen las estructuras, todo ello en relación con el proceso de islamización y las variaciones en el ritual de enterramiento; aunque aún sea prematuro fundamentar esta hipótesis sin previa actuación arqueológica.

\section{Despoblado de Robaquel}

El pequeño valle fluvial abierto por el río Alfaguara (<al-Fawwāra: fuente) concentra en su margen izquierda hasta cuatro enclaves arqueológicos que hemos denominado: Llanillos del Piloncillo, despoblado de Robaquel, Peñón homónimo y Llanos del Tejar. Nos centramos aquí en el enclave de mayor importancia, localizado en un cerro de escaso relieve elevado a orillas del curso fluvial, en el que aún se conservan elementos constructivos a ras de suelo de sumo valor patrimonial ${ }^{59}$. El yacimiento presenta gran concentración de material arqueológico, fundamentalmente motivado por la densidad de tejas, en contraste con el enclave cercano del Llanillo del Piloncillo, sobre el que habremos de volver.

El espacio de hábitat se encuentra inmediato al manantial de la Alfaguara (Cañada de la Fuente), provisto de sistema productivo adyacente, no lejos de otras tres surgencias naturales: Sierpes (Cisneras), Nacimiento de Tolox y Piloncillo, acorde a las necesidades de establecer una agricultura de regadío. Las estructuras visibles, relacionadas con espacios domésticos, emplean mampuestos autóctonos de calizas y travertinos. Los conjuntos cerámicos que predominan son de tradición emiral según sus características técnicas y tipológicas, sin rastro de los vidriados altomedievales del siglo x. La dispersión y concentración del material arqueológico da buena cuenta de las dimensiones del yacimiento y su importancia en el territorio. Nuevamente son frecuentes las tinajas islámicas con cordones digitados y las tejas digitadas con meandros, características de los siglos IX y X,

58 AHPG, LP n.o 6801, fol. 67v.

59 Sobre la localización y caracterización del despoblado de Robaquel o Alfaguara, véase: MARMOLEjo Cantos, Históricas y arqueológicas del Medievo en Coin, pp. 216-221 y "Castillos y despoblados medievales de Tolox», conferencia impartida en Tolox el 5 de diciembre de 2015. 
ESTRUCTURAS DE POBLAMIENTO EN TOLOX (MÁLAGA). LA OCUPACIÓN DEL TERRITORIO Y LA EXPLOTACIÓN DE SUS RECURSOS EN LA EDAD MEDIA FRANCISCO MARMOLEJO CANTOS

junto a grandes restos de escorias de reducción y esponjas férricas. La zona destinada a la transformación del hierro estaría ubicada en el sector norte del yacimiento, por encima del caserío; mientras que la procedencia del mineral susceptible de explotación cabría encontrarlo en la mineralización de las rocas carbonatadas (incluso en las peridotitas), pudiendo ser transportado desde el cercano pago de Ferreira (hoy Ferreila) ${ }^{60}$.

Por otro lado, en las faldas del pequeño peñón de Robaquel, a pocos pasos del cerro, hemos podido apreciar estructuras de enterramiento, posiblemente asociadas al poblado, junto a cerámica medieval en porcentaje exiguo. Los Robaqueyles figuran en las nóminas de vecinos moriscos de Monda, Istán y Tolox ${ }^{61}$. El topónimo en cuestión no aparece siquiera en cartografía histórica, por lo que hemos tenido que recurrir a testimonios orales de los vecinos para su correcta localización ${ }^{62}$. Dicho lo cual, este despoblado fue citado por el investigador Carlos Gozalbes Cravioto, habida cuenta que el Diccionario de Medina Conde parecía ubicarlo por la zona de Alhaurín de la Torre ${ }^{63}$.

La densidad de poblamiento en la zona, de clara vocación agrícola, está vinculada a las surgencias kársticas de la Alfaguara, algunas con depósitos tobáceos, así como al curso fluvial homónimo que vertebra el territorio. Se percibe gran diversidad de recursos en relación directa con las discontinuidades litológicas. Las huertas se prodigan por las terrazas fluviales del Cuaternario, circunscritas a la parte baja del valle, donde se concentran todas las roturaciones hasta contactar con las calizas, observándose bancales irrigados en peridotitas en la orilla opuesta. Decididamente, la puesta en explotación del valle debe remontarse a la Alta Edad Media, perviviendo esa intensa ocupación agrícola hasta nuestros días, hasta el punto de llegar a ponerse en cultivo sustratos no roturables. Esta limitación física, impuesta por los suelos y la topografía, unida a la fragmentación de la propiedad iniciada en época bajomedieval, con toda seguridad, impide apreciar excedentes agrícolas susceptibles de comercializar.

La importancia de esta agricultura de subsistencia debió complementarse con las múltiples actividades productivas vinculadas a la explotación del hierro: desde la elaboración de carbón y la extracción de mineral, hasta su transporte, reducción en hornos, elaboración de artefactos y distribución. Sin descartar que la elección y ocupación del enclave como asentamiento pueda estar relacionada con la accesibilidad al mineral de hierro y la disponibilidad de agua y bosques, a fin de mantener la actividad siderúrgica.

60 Marmolejo Cantos y SÁnchez Guerra, «Porticate, alquería altomedieval y centro siderúrgico en la Sierra de las Nieves (Málaga)», p. 46.

${ }^{61}$ AHPG, LP n. ${ }^{\circ}$ 6.800, LP n. ${ }^{\circ} 6.801$ y LP n. ${ }^{\circ} 6.747$.

62 En la búsqueda de información, han sido fundamentales las diversas encuestas realizadas a Paco Gil, cabrero como su padre, en cuya memoria pervive la toponimia desaparecida de época morisca, lugares como Ferreyra, Çela, Xaurife, Gatuz, Robaquel, Alfaguara o Murta son cumplidos ejemplos de la importancia de recabar testimonios orales en las tareas de campo. Igualmente deseo hacer llegar también mi reconocimiento y gratitud a Juan González Martín, Juan Nasr, Carlos Gozalbes Cravioto, Diego J. Sánchez Guerra, Amparo Vera Puerto, Ana Belén Merchán Reina y Pilar Gil Fernández.

63 Gozalbes Cravioto, Carlos. «El patrimonio arqueológico de Alhaurín de la Torre: entre el desastre y la esperanza». En Actas I y II del Ciclo de Conferencias: Alhaurín en su Historia. Alhaurín de la Torre: Ayuntamiento, 2003, pp. 79-90. 
ESTRUCTURAS DE POBLAMIENTO EN TOLOX (MÁLAGA). LA OCUPACIÓN DEL TERRITORIO Y LA EXPLOTACIÓN DE SUS RECURSOS EN LA EDAD MEDIA

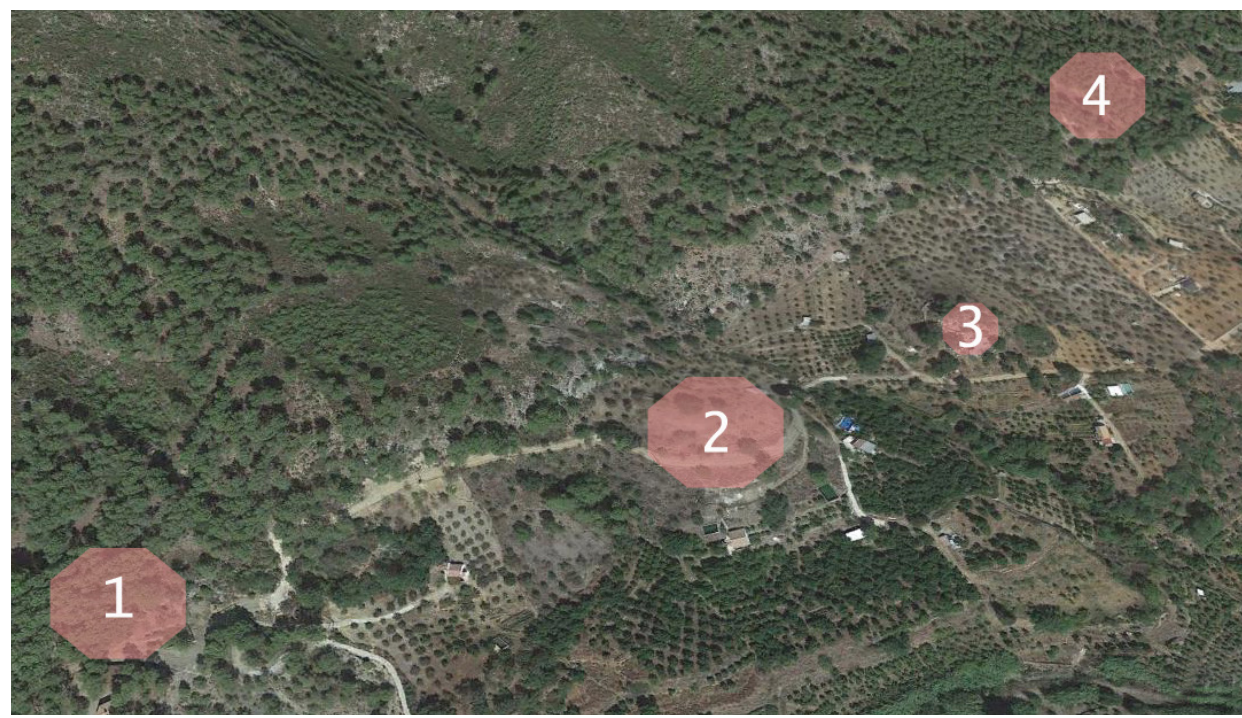

Figura 8. Localización de los enclaves documentados en el valle del río Alfaguara: 1. Llanillos del Piloncillo; 2. Despoblado de Robaquel (Alfaguara); 3. Peñón de Robaquel; 4. Llanos del Tejar. Mapa: F. Marmolejo.

\section{Llanos del TeJar}

En la margen izquierda del río Alfaguara, en el pinar que domina el valle, se han hallado casualmente dos puntas de proyectil de uso militar, sin más material arqueológico asociado. La primera pieza es una punta de lanza de hierro forjado de doble filo, con nervio central y enmangue tubular para insertar el astil. Su longitud total alcanza unos $27 \mathrm{~cm}$ (enmangue de $13 \mathrm{~cm}$ y extremo distal plano de $14 \mathrm{~cm}$ ), siendo su mayor anchura de $3 \mathrm{~cm}$. El segundo ejemplar hallado es una punta de hierro de sección cuadrada, con pedúnculo alargado de sección circular. Su anchura máxima no rebasa los $0,7 \mathrm{~cm}$; la longitud de la punta alcanza los $9,5 \mathrm{~cm}$ y el pedúnculo presenta casi el doble, unos $19,5 \mathrm{~cm}$ de largo. La pieza conserva indicios de haber sido disparada, pues ha perdido su extremo distal, acabado en punta, tras intentarse enderezar recientemente.

Nos resistimos a vincular estas piezas con las comunidades de carácter campesino asentadas en la Alfaguara. A nuestro parecer, dicho armamento de carácter ofensivo debemos ponerlo en relación con la existencia de un centro siderúrgico dedicado a la producción y manufactura de estas piezas, tal vez el de Robaquel antes descrito. De no ser así, solo queda buscar su procedencia en algún reducto fortificado provisto de guarnición militar, con posible localización en las cercanías, aunque desconozcamos su realidad arqueológica en el estado actual de la investigación ${ }^{64}$.

64 Marmolejo Cantos y Sánchez Guerra, «Porticate, alquería altomedieval y centro siderúrgico en la Sierra de las Nieves (Málaga)», pp. 33-51. 
ESTRUCTURAS DE POBLAMIENTO EN TOLOX (MÁLAGA). LA OCUPACIÓN DEL TERRITORIO Y LA EXPLOTACIÓN DE SUS RECURSOS EN LA EDAD MEDIA FRANCISCO MARMOLEJO CANTOS

Se asienta en el entorno de la moderna ermita de la virgen de las Nieves, también en la margen izquierda del río de los Horcajos, a pocos pasos del despoblado de Robaquel. Ocupa en la actualidad una zona densa de pinar a media ladera, que los lugareńos llaman los Llanillos del Piloncillo, por situarse próximo a la conocida fuente homónima. El material arqueológico se encuentra disperso, sin grandes concentraciones, muy rodado y fragmentado debido a las intensas labores de reforestación. El indicador cronológico que mejor define el yacimiento es la cerámica común paleoandalusí de gruesos desgrasantes modelada a torneta ${ }^{65}$, sin que aparezcan los vidriados islámicos, aunque son frecuentes las tinajas con asas de aleta de tiburón y los cordones digitados. Registro este más que suficiente para definir una ocupación islámica de época altomedieval, sin descartar otras de mayor antigüedad en niveles inferiores. El grado de concentración de material es mucho menor que en Robaquel, motivado quizá por la práctica ausencia de tejas, aunque su extensión y dispersión sea aceptable para su caracterización como despoblado.

En su entorno inmediato sobresalen los cultivos irrigados a orillas del curso fluvial, los mismos que hemos descrito para el cercano cerro de Robaquel. Se dan condiciones desfavorables para el cereal de secano pese a existir pequeñas eras y tierras de labor; a lo sumo están asociadas al caserío disperso, muy lejos de las grandes extensiones que asoman en Ardite y la Jara. Hacia el norte se descubren suelos forestales con importantes reservas madereras y recursos susceptibles de explotación ganadera y cinegética; allí proliferan los pequeńos núcleos agrícolas de montańa, todos vinculados a fuentes y manantiales provistos de abrevadero, lo cual permite valorar el peso de la tradición ganadera en el territorio.

\section{Despoblado del Moralejo}

Los datos proporcionados por el registro cerámico nos remiten con fundamento a época bajomedieval, a diferencia de los enclaves preislámicos y altomedievales que hemos visto hasta el momento. Se asienta también aprovechando la media ladera de un cerro a espaldas de Río Grande, al pie de la carretera que se dirige a Alozaina, no lejos de la alquería de los Valles y de los villares de Boliges. Ocupa una extensión considerable del cerro, sin que se observen estructuras defensivas o domésticas, aunque es bien perceptible el aterrazamiento escalonado para establecer las viviendas, con menudas y alargardas albarradas amortizando los derrumbes del caserío.

Los conjuntos cerámicos más frecuentes son tardíos y presentan claras similitudes con los existentes en el cercano yacimiento de los Villares. En líneas generales, el repertorio decorativo acoge piezas vidriadas en verde para candiles, jarritas, redomas y ataifores, mientras los melados están presentes en ataifores, cazuelas y marmitas. La etapa bajomedieval está ampliamente representada con cazuelas de bases convexas, asas pegadas al

65 Véase sobre estos conjuntos Alba Calzado y Gutiérrez Lloret, «Las producciones de transición al Mundo Islámico», pp. 585-613. 
ESTRUCTURAS DE POBLAMIENTO EN TOLOX (MÁLAGA). LA OCUPACIÓN DEL TERRITORIO Y LA EXPLOTACIÓN DE SUS RECURSOS EN LA EDAD MEDIA FRANCISCO MARMOLEJO CANTOS

cuerpo y labio en ala, además de las características marmitas de paredes finas meladas al interior $^{66}$. Se percibe una amplia variedad en ataifores; los más frecuentes son los vidriados en verde claro al interior, con paralelos cercanos en los vertederos de Cártama, junto a otros de sección quebrada vidriados en ambas superficies ${ }^{67}$. Si bien en el sector más elevado se evidencian producciones más antiguas, de composición muy tosca, paredes gruesas y arcillas poco decantadas, con buena presencia de vajilla de almacenamiento modelada a mano. De igual modo, en los perfiles abiertos por las cárcavas se aprecia material de fácil identificación tipológica, siendo más que evidente la intromisión de otras culturas materiales, desde ímbrices romanos con digitaciones hasta cuencos y platos de tradición castellana, definiendo un ámbito cronológico más amplio que el que veremos luego en los villares de Boliges.

En el sector suroeste, a mayor cota de altura, hemos conseguido localizar su necrópolis previa indicación del propietario de los terrenos. Subyacen seis estructuras de enterramiento muy afectadas por la apertura de un camino secundario, además de material óseo disperso en un área de $600 \mathrm{~m}^{2}$ en un excelente estado de conservación, sin la menor evidencia de cerámica ${ }^{68}$.

De otro lado, la superficie hidráulica asociada al despoblado se nutre de la acequia de Jorox, en la margen izquierda de Río Grande y a cierta distancia del espacio de residencia, contando con un pozo cercano para abastecimiento, función que debió compartir con el arroyo del Moralejo. En toda la vertiente del despoblado, a primera vista improductiva y ajena al aprovechamiento agrícola, adquieren importancia los cultivos arbóreos de secano, sin descuidar las pequeñas superficies destinadas a cereal, que a todas luces prosperaban por encima del arroyo evitando las heladas. No obstante, debemos destacar la importancia del moral y la vid en la vida económica de estas comunidades, en especial como producto destinado al comercio en zonas deficitarias del valle, así como las actividades enfocadas a la cría de gusanos y la producción de seda. En tal sentido, ni que decir tiene, Tolox se cuenta entre los principales centros sericultores de la circunscripción malagueña al menos desde época nazarí, tradición productiva que se desvanece a principios del siglo XVIII.

66 Estos tipos cerámicos se documentan en Fernández Navarro, Esteban. Tradición tecnológica de la cerámica de cocina de época almohade-nazarí. Granada: Grupo Investigación Toponimia, Historia y Arqueología, 2008.

67 Sobre las producciones cerámicas perceptibles en este despoblado encontramos paralelos en García Porras, Alberto. "La distribución de productos cerámicos entre la época almohade y la nazarí. El caso de El Castillejo (Los Guájares, Granada)». Arqueoweb. Revista sobre Arqueología en Internet, 2007, vol. 9, no 1; Melero García, Francisco. «El vertedero medieval de Cártama, Málaga: las cerámicas de los pozos de época emiral y califal». Arqueología y Territorio Medieval, 2009, vol. 16, pp. 33-52; NAVArro Palazón, Julio. La cerámica islámica en Murcia. Murcia: Centro Municipal de Arqueología, 1986; Cressier, Patrice; Riera Frau, M. a Magdalena y Roselló Bordoy, Guillermo. "La cerámica tardo almohade y los orígenes de la cerámica nasrí». En A cerâmica medieval no Mediterrâneo Occidental. Actas do IV Congreso Internacional Lisboa, 16-22 novembro 1987. Mértola: Campo Arqueológico de Mértola, 1991, pp. 215-246.

${ }_{68}$ El espacio de enterramiento se encuentra en las coordenadas centrales UTM (Datum ETRS89): X: 332.043,92; Y: 4.064.123,23. 
ESTRUCTURAS DE POBLAMIENTO EN TOLOX (MÁLAGA). LA OCUPACIÓN DEL TERRITORIO Y LA EXPLOTACIÓN DE SUS RECURSOS EN LA EDAD MEDIA FRANCISCO MARMOLEJO CANTOS

\section{Villares de Boliges}

Enclave situado sobre una ladera de suave pendiente en la margen izquierda del río Almozara (<al-ma'ṣara: molino de aceite), poco antes de su confluencia con Río Grande, desde donde se dominan varios ejes de comunicación: el camino real a Tolox y el camino de Alozaina, ambos con dirección a la serranía de Ronda ${ }^{69}$. Vía de primer orden -esta última- para la conexión entre las ciudades de Málaga y Ronda tras quedar militarizada la frontera del Turón en el siglo xIv.

Con carácter previo a cualquier planteamiento, creemos oportuno caracterizar el yacimiento, pues presenta particularidades formales con respecto a los demás despoblados bajomedievales documentados en Río Grande ${ }^{70}$. En esta línea, los restos materiales visibles en superficie, a nuestro entender, respaldan la hipótesis de que no se trata de un despoblado sino de un centro religioso, posiblemente tipo rábita o zäwiya, en el que podemos documentar el tránsito del mundo almohade al nazari ${ }^{71}$.

La ordenación del espacio responde a los principios enunciados por Miquel Barceló y colaboradores ${ }^{72}$. El espacio de hábitat se prodigaba por el secano adyacente al espacio irrigado, por encima de la acequia de Bolijas (Bolixes) ${ }^{73}$. La superficie irrigada se estructuraba en tableros de cultivo de disposición escalonada, extendiéndose desde la acequia principal hasta contactar con la orilla izquierda del río Almozara, por encima de la zona inundable, donde aún se perciben las ruinas de un caserón provisto de cárcavo (posible molino). Por su parte, el secano de mayor pendiente quedó cubierto de olivares, con zonas destinadas probablemente al cereal, quedando hoy vestigios de antiguas eras de labor. Ni que decir tiene que, entre los recursos disponibles, se encontrarían los fluviales derivados de la pesca en Río Grande y sus afluentes, actividad esencial para la subsistencia de estas comunidades.

69 Más información sobre los villares de Boliges (ss. XII-Xv) en Marmolejo Cantos, Históricas y arqueológicas del Medievo en Coín, pp. 216-221. Véase también «Una rábita o zāwiya en la vega de Río Grande (Málaga): indicadores para su localización geográfica y propuesta de estudio», 2015, obra colectiva en imprenta.

70 González Martín, Juan. «Aproximación a la investigación arqueológica de los yacimientos medievales del término municipal de Coín». En Morillo del Castillo, M. a del Carmen y Pérez GonzÁlez, Salvador (coords.). Guadalhórcete al sur de al-Andalus. Pizarra (Málaga): Redagua, 2007, pp. 179-191; Marmolejo Cantos, Poblamiento andalusi en la cuenca fluvial de Rio Grande (Málaga). Véase también: MaRmolejo Cantos, Francisco. Comunidades rurales en el alfoz de Coín a fines de la Edad Media. Medio físico y transformaciones en la cuenca media de Río Grande (Málaga). Editorial Académica Española, 2016.

${ }_{71}$ Ibidem. Otra posible rábita en término de Tolox se halla al oeste de la población, donde aún pervive dicho topónimo aplicado a una fuente y un puerto de montańa.

72 Consúltense los trabajos de Barceló, Miquel; Kirchner, Helena y Navarro, Carmen. El agua que no duerme. Fundamentos de la arqueología hidráulica andalusí. Granada: Fundación El Legado andalusí, 1996; Glick, Thomas F. Islamic and Christian Spain in the early middle ages. Princeton: Princeton University Press, 1996; Guinot Rodríguez, Enric y Esquilache Martí, Ferran. Moncada i l'Orde del Temple en el segle XIII. Una comunitat rural de l'Horta de València en temps de Jaume I. València: Institució Alfons el Magnànim, 2010.

73 Toda esta zona figura bajo el topónimo Boliges o Bolixe en documentación del siglo XVI (AHPG, LP n. ${ }^{\text {os }} 6.800$ y 6.801), denominación que usaremos en adelante para diferenciarlo de otros villares cercanos como el de Arroyo Hondo (Alozaina), el de Algane (Coín) o el de Alpujata (Monda). 
ESTRUCTURAS DE POBLAMIENTO EN TOLOX (MÁLAGA). LA OCUPACIÓN DEL TERRITORIO Y LA EXPLOTACIÓN DE SUS RECURSOS EN LA EDAD MEDIA FRANCISCO MARMOLEJO CANTOS

El camino que atraviesa el yacimiento arqueológico, en paralelo a la acequia principal, permite observar los perfiles estratigráficos en algunos sectores, dejando al descubierto algunas estructuras domésticas, levantadas en mampostería con materiales extraídos a pie de obra. El registro arqueológico no deja lugar a duda en cuanto a su datación en periodo almohade y nazarí, sobresaliendo las producciones de esta última etapa, con las características jarritas esgrafiadas y los ataifores vidriados en verde sólo al interior. Esta serie, tan diversa y heterogénea, permite precisar la cronología del yacimiento, atendiendo a las evoluciones en su tipología y en el repertorio decorativo. En nuestro caso, se aprecian ejemplares con paredes curvas o quebradas; vidriados monocromos en melado o verde; tanto en ambas superficies como solo al interior (s. XII-XV).

Pero, si hay algo que destacar del material arqueológico, sin duda, son las piedras pulimentadas de forma ovalada y pequeño tamaño, que relacionamos directamente con elementos para la purificación $"$ menor ${ }^{74}$, aun a sabiendas de que la zona cuenta con abundantes recursos hídricos. No es tanto por el hecho de su existencia, sino por la cantidad tan inusual de estos elementos, lo que lleva a inclinarnos decididamente por un centro religioso islámico, tipo rábita o zāwiya atendiendo a su emplazamiento.

Desde los textos históricos, que relatan el alzamiento morisco, conocemos la intervención de un morabito en esta zona de Río Grande, en el camino de Tolox a Coín, que acudió con su jaquita a recibir a El Galipe, uno de los cabecillas de la revuelta, a darle su baraka y ofrecerle protección en la batalla:

«Entre otras cosas que ganaron los soldados este día, fue una haquita en que venía un moro santo al recibimiento de su nuevo rey y a echarle la bendición, porque era grande la confianza que aquellos serranos bárbaros tenían en él, y pensaban hacer grandes cosas con su presencia» ${ }^{75}$.

Diversas consideraciones podemos entresacar de este pasaje; la primera es la existencia de morabitos y posiblemente rábitas o zäwiya-s nada menos que en la segunda mitad del siglo XVI, pues todo apunta a que estos centros religiosos de carácter rural, tan apartados y aislados del mundo urbano, van a pervivir durante esta centuria, pasando inadvertidos para los nuevos pobladores, sin descartar que quedasen amparados por las capitulaciones en un primer momento. Interesa destacar, en segundo lugar, el papel y cometido que mantiene este santón local de bendecir al jefe militar, convocar combatientes e interceder en la batalla, así como la confianza que los vecinos y autoridades tienen en su persona, pues "pensaban hacer grandes cosas con su presencia». De otro lado, no parece que fuera un militar adiestrado, aunque del relato se deduce su participación directa en el combate, al menos sabemos que perdió su jaquita ${ }^{76}$.

74 Epalza, Mikel de. La rábita en el islam. Estudios interdisciplinares. Alacant: Universitat d'Alacant; Sant Carles de la Ràpita: Ajuntament, 2004, p. 20.

75 Mármol Carvajal, Luis del. Historia del rebelión y castigo de los moriscos del Reyno de Granada. Madrid: en la Imprenta de Sancha, 1797, capítulo XI, p. 403.

76 Ibidem, p. 403. 
ESTRUCTURAS DE POBLAMIENTO EN TOLOX (MÁLAGA). LA OCUPACIÓN DEL TERRITORIO

Y LA EXPLOTACIÓN DE SUS RECURSOS EN LA EDAD MEDIA

FRANCISCO MARMOLEJO CANTOS

\section{Ardite}

En la zona dominada por el cerro de Ardite hemos podido documentar dos yacimientos medievales dentro del término municipal, claves para comprender los procesos de reordenación agraria y para estudiar los sistemas de captación fluvial de Río Grande, en su margen izquierda. El primero de ellos se sitúa al oeste de El Cortao y conserva conjuntos cerámicos propios de época altomedieval, entremezclados con otras producciones modernas. Por su cronología, no descartamos que pueda corresponderse con la alquería de Ardite citada en los textos árabes, donde nació el afamado gramático Ibn al-Tarawa ${ }^{77}$.

El segundo yacimiento se localiza poco después de la confluencia del arroyo de los Valles con Río Grande, segregado físicamente por el camino de Ardite, por encima del espacio hidráulico. En este caso, encontramos producciones modeladas a torno, con pastas de textura compacta y tonos claros, parduzcos y anaranjados, donde el siglo XII está ampliamente representado con ataifores de perfil quebrado y algunos ejemplares de cazuelas con asas múltiples, piezas que guardan relación tipológica con las documentadas en Granada ${ }^{78}$.

El peso de los agrosistemas irrigados es incuestionable, pese a que las ampliaciones del sistema hidráulico distorsionan la lectura del paisaje. Con más razón, aquí, la actividad ganadera parece mantener un papel secundario, únicamente se percibe por su inmediatez con la dehesa de Alozaina y con la majada de Buzeyte, según vemos en los deslindes y en los libros de Poblamiento de Guaro y Tolox ${ }^{79}$.

\section{Conclusiones}

De todos es sabido que la montaña se convierte en lugar de refugio forzoso en etapas de inestabilidad político-social. Desde un enfoque arqueológico, habría que preguntarse cómo se manifiesta el poder y su capacidad de control en zonas tan distantes y alejadas de los grandes centros urbanos, sin dejar de indagar las causas concretas del vacío demográfico que detectamos desde el siglo xII en el interior montañoso.

El territorio de Tolox vive un proceso de concentración poblacional en periodo altomedieval, iniciado probablemente antes de la irrupción del Islam en la península. Desde luego, sus características geográficas y topográficas favorecen el establecimiento humano durante los primeros siglos de al-Andalus. Del estudio llevado a cabo, se desprende una primera ocupación protagonizada por pequeñas comunidades preislámicas de carácter rural, con élites locales fuertemente implantadas y una estructura de poblamiento, poco

77 YaQut Al-Hamawi. Kitab mu yam al-buldan, ed. Leipzig, 1866-1873, vol. I, p. 208; trad. en 'Авр AL-KaRIM, Gamal. La España musulmana en la obra de Yaqut (s. XII-XIII). Repertorio enciclopédico de ciudades, castillos y lugares de al-Andalus extraido del Mu'yam al-buldan (Diccionario de los países). Granada: Universidad de Granada, 1974; Peña Martín, Salvador. "Ibn al-Tarawa, Abu l-Husayn». En Lirola Delgado, Jorge (dir.). Biblioteca de Al-Andalus. Almería: Fundación Ibn Tufayl de Estudios Árabes, 2004, vol. 5, n.o 1.253, pp. 485-488.

78 Fernández Navarro, Tradición tecnológica de la cerámica de cocina de época almohade-nazarí.

79 AHPG, LP n.os $6.716,6.800$ y 6.801 . 
ESTRUCTURAS DE POBLAMIENTO EN TOLOX (MÁLAGA). LA OCUPACIÓN DEL TERRITORIO Y LA EXPLOTACIÓN DE SUS RECURSOS EN LA EDAD MEDIA FRANCISCO MARMOLEJO CANTOS

cohesionada, que hemos definido por su dispersión y aislamiento. Con anterioridad al siglo XII se abandona definitivamente el interior montañoso y se produce un despoblamiento generalizado de los enclaves de primera etapa. Surgen nuevas poblaciones de clara vocación agrícola que se implantarán en la cuenca fluvial de Río Grande, con mejores comunicaciones y economías orientadas al valle del Guadalhorce.

De lo expuesto, en nuestro marco geográfico predominan vestigios del pasado altomedieval en mayor porcentaje que cualquier otra cultura material, lo que convierte a Tolox y su territorio en zona clave para avanzar en el conocimiento que tenemos sobre la formación y consolidación de al-Andalus. La distribución espacial de los núcleos habitados para nada es homogénea en el territorio: los lugares escogidos para asentamiento se concentrarán en zonas próximas a Río Grande durante época romana y bajomedieval, muchos vinculados al regadío; en cambio, los enclaves prehistóricos y altomedievales se dispersarán por el interior montańoso de la sierra de las Nieves, prodigándose hasta la cuenca alta de Río Verde.

Nos parece sugerente estudiar los factores que inciden en esta reordenación del poblamiento, donde se busca una aproximación a las fértiles terrazas fluviales del Cuaternario y a las principales vías de comunicación. En nuestro caso, se dan múltiples circunstancias y no todas responden exclusivamente a razones políticas y socioeconómicas externas a estas comunidades. Entre los factores del proceso despoblador, está la incapacidad de la montańa de absorver el crecimiento demográfico, atendiendo a los límites físicos que suponen las pendientes acusadas y los suelos improductivos de calizas y peridotitas, de nula rentabilidad; lo que a su vez justifica la ocupación de áreas donde: poder introducir nuevas técnicas de cultivo, poder integrarse en los circuitos comerciales y, con todo, facilitar la inserción de la producción en el mismo. Como transfondo de ello, siempre aparece la necesidad de generar excedentes que intercambiar para contribuir con el fisco. Que sepamos, la extensión de los cultivos a sustratos no roturables y la excesiva fragmentación de la propiedad, consecuencia de la presión demográfica, creemos tuvo lugar en época bajomedieval; al menos es perceptible en los libros de poblamiento del siglo XVI ${ }^{80}$. Si bien sabemos que, con la desamortización de Madoz en el XIX, aumentaron de forma exponencial estas roturaciones, causando graves perjuicios a ganaderos y campesinos.

Por lo demás, entendiendo que estamos inmersos en un territorio de difícil estudio, lastrado por la dura geomorfología y el desapego por el medio rural, lo cual supone una ardua labor para investigadores y especialistas, se impone la necesidad de romper esta tendencia y dar los primeros pasos para superar el estancamiento histórico y arqueológico que padece la localidad. Hasta el momento se conocía únicamente el denominado Castillejo de Tolox que dimos a conocer en un trabajo de carácter divulgativo, en compañía de Diego J. Sánchez Guerra. De los pocos datos que hemos podido recabar, hemos conseguido ampliar esta nómina a un total de 12 asentamientos medievales, lo cual sigue siendo un porcentaje exiguo y poco representativo de la realidad arqueológica que nos depara el futuro. A estos podríamos añadir algunos hallazgos aislados en la cueva de la Espada, arroyo de los Pilones y Alcornocalejo, de los que daremos cuenta en próximas publicaciones. En tal sentido, nuestro propósito más inmediato no era otro que dejar esta

${ }^{80}$ AHPG, LP n. ${ }^{\circ 5} 6.747,6.800$ y 6.801 . 
ESTRUCTURAS DE POBLAMIENTO EN TOLOX (MÁLAGA). LA OCUPACIÓN DEL TERRITORIO Y LA EXPLOTACIÓN DE SUS RECURSOS EN LA EDAD MEDIA FRANCISCO MARMOLEJO CANTOS

primera aproximación al poblamiento rural de montaña, como paso previo a cualquier actuación arqueológica, con el ánimo de atraer la atención de estudiosos que respalden o mejoren nuestras conclusiones, desde luego sin dejar de cuestionar ninguno de nuestros aciertos.

\section{REFERENCIAS BibliográFICAS}

'Abd AL-Karim, Gamal. La España musulmana en la obra de Yaqut (s. XII-XIII). Repertorio enciclopédico de ciudades, castillos y lugares de al-Andalus extraido del Mu yam al-buldan (Diccionario de los paises). Granada: Universidad de Granada, 1974.

Acién Almansa, Manuel. «La islamización del SE de al-Andalus. Los datos arqueológicos». En Boldrini, Enrica y Francovich, Riccardo (eds.). Acculturazione e mutamenti. Prospettive nell'Archeologia Medievale del Mediterraneo. Firenze: All'Insegna del Giglio, 1995, pp. 13-28.

Alba Calzado, Miguel A. y Gutiérrez Lloret, Sonia. "Las producciones de transición al Mundo Islámico: el problema de la cerámica paleoandalusí (siglos viII y IX)». En Bernal Casasola, Darío y Ribera i Lacomba, Albert (eds.). Cerámicas hispanorromanas. Un estado de la cuestión. Cádiz: Universidad de Cádiz, 2006, pp. 585-613.

Azuar Ruiz, Rafael. "Campesinos fortificados frente a conquistadores feudales en los valles del Vinalopó». En Jover Maestre, Francisco Javier y Navarro Poveda, Concepción (coords.). De la Medina a la Vila. II Jornadas de Arqueologia Medieval. Alicante: Museo Arqueológico de Alicante, 2004, pp. 263-291.

Barceló, Miquel; Kirchner, Helena y Navarro, Carmen. El agua que no duerme. Fundamentos de la arqueología hidráulica andalusi. Granada: Fundación El Legado andalusí, 1996.

Carriazo y Arroquia, Juan de Mata. En la frontera de Granada. Sevilla: Facultad de Filosofía y Letras, 1971.

Correspondencia del conde de Tendilla. Vol. I (1508-1509), ed. Emilio Meneses García. Madrid: Real Academia de la Historia, 1973.

Cressier, Patrice, Riera Frau, M. a Magdalena y Roselló Bordoy, Guillermo. "La cerámica tardo almohade y los orígenes de la cerámica nasrí». En A cerâmica medieval no Mediterrâneo Occidental. Actas do IV Congreso Internacional Lisboa, 16-22 novembro 1987. Mértola: Campo Arqueológico de Mértola, 1991, pp. 215-246.

Epalza, Mikel de. La rábita en el islam. Estudios interdisciplinares. Alacant: Universitat d'Alacant; Sant Carles de la Ràpita: Ajuntament, 2004.

Fernández Navarro, Esteban. Tradición tecnológica de la cerámica de cocina de época almohadenazari. Granada: Grupo Investigación Toponimia, Historia y Arqueología, 2008.

Fernández Ruiz, Juan y Márquez Romero, José Enrique. «Territorio y poblamiento humano en el río Grande». Baetica, 2001, vol. 23, pp. 263-294.

García Porras, Alberto. «La distribución de productos cerámicos entre la época almohade y la nazarí. El caso de El Castillejo (Los Guájares, Granada)». Arqueoweb. Revista sobre Arqueologia en Internet, 2007, vol. 9, no 1.

GuICK, Thomas F. Islamic and Christian Spain in the early middle ages. Princeton: Princeton University Press, 1996.

GonzÁlez Martín, Juan. «Aproximación a la investigación arqueológica de los yacimientos medievales del término municipal de Coín». En Morillo del Castillo, M. a del Carmen y Pérez González, Salvador (coords.). Guadalhórcete al sur de al-Andalus. Pizarra (Málaga): Redagua, 2007, pp. 179-191. 
ESTRUCTURAS DE POBLAMIENTO EN TOLOX (MÁLAGA). LA OCUPACIÓN DEL TERRITORIO Y LA EXPLOTACIÓN DE SUS RECURSOS EN LA EDAD MEDIA FRANCISCO MARMOLEJO CANTOS

Gozalbes Cravioto, Carlos. «El patrimonio arqueológico de Alhaurín de la Torre: entre el desastre y la esperanza». En Actas I y II del Ciclo de Conferencias: Alhaurín en su Historia. Alhaurín de la Torre: Ayuntamiento, 2003, pp. 79-90.

Guinot Rodríguez, Enric y Esquilache Martí, Ferran. Moncada i l'Orde del Temple en el segle XIII. Una comunitat rural de l'Horta de València en temps de Jaume I. València: Institució Alfons el Magnànim, 2010.

Ladero Quesada, Miguel Ángel. «El duro fisco de los emires». Cuadernos de Historia, 1969, vol. 3, pp. 321-334.

Ladero Quesada, Miguel Ángel. «La defensa de Granada a raíz de su conquista. Comienzos de un problema». Miscelánea de Estudios Árabes y Hebraicos. Sección Árabe-Islam, 1967, vol. 16, pp. 7-46.

López de Coca Castañer, José Enrique. La tierra de Málaga a fines del siglo XV. Granada: Universidad de Granada, 1975.

López García, Esteban. «Regadío de origen andalusí en la Sierra de las Nieves. El caso de Tolox (1485-1572)». Takurunna, 2012, vol. 2, pp. 187-216.

Mármol Carvajal, Luis del. Historia del rebelión y castigo de los moriscos del Reyno de Granada. Madrid: en la Imprenta de Sancha, 1797.

Marmolejo Cantos, Francisco. «La alquería bajomedieval de los Padules. La evolución de un deire consagrado a Santo Bítar». Debates de Arqueología Medieval, 2014, vol. 4, pp. 111-129.

Marmolejo Cantos, Francisco. Comunidades rurales en el alfoz de Coin a fines de la Edad Media. Medio físico y transformaciones en la cuenca media de Río Grande (Málaga). Editorial Académica Española, 2016.

Marmolejo Cantos, Francisco. El castillo de Benamaquis. Limites y localización histórica. Coín: edición digital, 2014.

Marmolejo Cantos, Francisco. Históricas y arqueológicas del Medievo en Coin. Málaga: edición digital, 2009.

Marmolejo Cantos, Francisco. La Edad Media en Coin y su alfoz. Coín: Asociación Arqueológica y Excmo. Ayuntamiento, 2014.

Marmolejo Cantos, Francisco. Poblamiento andalusi en la cuenca fluvial de Río Grande (Málaga). Explotación y defensa del territorio en la Edad Media. Málaga: Asociación Arqueológica de Coín, Guadalhorce y Sierra de las Nieves, 2015.

Marmolejo Cantos, Francisco y Sánchez Guerra, Diego J. «La fortaleza de la Teja y la alquería de Gaimón. Un hịnn con alquería en los confines de Monda y Tolox». Arqueología Medieval, n. ${ }^{\circ} 139,2013$, en https://goo.gl/PCoAN0.

Marmolejo Cantos, Francisco y Sánchez Guerra, Diego J. «Porticate, alquería altomedieval y centro siderúrgico en la Sierra de las Nieves (Málaga)». Revista del Centro de Estudios Históricos del Reino de Granada, 2014, vol. 26, pp. 33-51.

Martínez Enamorado, Virgilio. «Apuntes sobre la villa de Tolox (Málaga) a partir de su libro de repartimiento (1572): una sociedad morisca en trance de desaparición». En BenLABBaH, Fatiha y Chalkha, Achouak (coords.). Los moriscos y su legado desde ésta y otras laderas. Rabat: Instituto de Estudios Hispano-Lusos, 2010, pp. 397-422.

Melero García, Francisco. «El vertedero medieval de Cártama, Málaga: las cerámicas de los pozos de época emiral y califal». Arqueología y Territorio Medieval, 2009, vol. 16, pp. 33-52.

Morales, Ambrosio de. Las antigüedades de las ciudades de España. Madrid: en la Oficina de Don Benito Cano, 1792, vol. IX.

Navarro Palazón, Julio. La cerámica islámica en Murcia. Murcia: Centro Municipal de Arqueología, 1986. 
ESTRUCTURAS DE POBLAMIENTO EN TOLOX (MÁLAGA). LA OCUPACIÓN DEL TERRITORIO

Y LA EXPLOTACIÓN DE SUS RECURSOS EN LA EDAD MEDIA

FRANCISCO MARMOLEJO CANTOS

Peña Martín, Salvador. «Ibn al-Tarawa, Abu 1-Husayn». En Lirola Delgado, Jorge (dir.). Biblioteca de Al-Andalus. Almería: Fundación Ibn Tufayl de Estudios Árabes, 2004, vol. 5, n. ${ }^{\circ}$ 1.253, pp. 485-488.

Pérez Berrocal, José Antonio. «Tres vasos decorados de la cueva de la Tinaja». Jábega, 1979, vol. 25, pp. 9-13.

Pérez Berrocal, José Antonio y Moreno Wallace, Loreto. "Informe preliminar. Campaña de exploraciones en el complejo "Hoyos del Pilar"». Monografías Espeleológicas, 1973, vol. 2, pp. 4-10.

Pulgar, Fernando del. Crónica de los señores Reyes Católicos don Fernando y doña Isabel. Valencia: en la Imprenta de Benito Monfort, 1780.

Ramos Ibaseta, José Ramón. Política ganadera de los Reyes Católicos en el obispado de Málaga. Málaga: Diputación Provincial de Málaga, 1988.

Sánchez Guerra, Diego J. «El Bombo y la casa fuerte del marqués de Villena. Un paseo por la historia y la memoria de Monda», 2016, https://goo.gl/YLyveW.

Sánchez Guerra, Diego J. "Tolox en un dibujo de mediados del siglo xviII del Catastro de Ensenada», 2013, http://airesdemonda.blogspot.com.es/2013/10/tolox-en-un-dibujo-demediados-del.html.

YaQut Al-Hamawi. Kitab mu'yam al-buldan, ed. Leipzig, 1866-1873. 